Published in final edited form as:

J Am Chem Soc. 2019 December 18; 141(50): 19859-19869. doi:10.1021/jacs.9b10320.

\title{
Isolation and Study of Ruthenium-Cobalt Oxo Cubanes Bearing a High-Valent, Terminal Ruv-Oxo with Significant Oxyl Radical Character
}

\author{
Jaruwan Amtawong ${ }^{\dagger}$, David Balcells ${ }^{\ddagger}$, Jarett Wilcoxen $\S$, Rex C. Handford ${ }^{\dagger}$, Naomi Biggins ${ }^{\dagger}$, \\ Andy I. Nguyen ${ }^{\dagger, \|}$, R. David Britt $\$$, T. Don Tilley ${ }^{\star}, \dagger, \|$ \\ tDepartment of Chemistry, University of California at Berkeley, Berkeley, California 94720-1460, \\ United States \\ ¥Hylleraas Centre for Quantum Molecular Sciences, Department of Chemistry, University of Oslo, \\ P.O. Box 1033, Blindern, 0315 Oslo, Norway \\ $\S$ Department of Chemistry, University of California, Davis, California 95616, United States \\ "Chemical Sciences Division, Lawrence Berkeley National Laboratory, Berkeley, California 94720, \\ United States
}

\section{Abstract}

\begin{abstract}
High-valent $\mathrm{Ru}^{\mathrm{V}}$-oxo intermediates have long been proposed in catalytic oxidation chemistry, but investigations into their electronic and chemical properties have been limited due to their reactive nature and rarity. The incorporation of $\mathrm{Ru}$ into the $\left[\mathrm{Co}_{3} \mathrm{O}_{4}\right]$ subcluster via the singlestep assembly reaction of $\mathrm{Co}^{\mathrm{II}}(\mathrm{OAc})_{2}\left(\mathrm{H}_{2} \mathrm{O}\right)_{4}(\mathrm{OAc}=$ acetate $)$, perruthenate $\left(\mathrm{RuO}_{4}^{-}\right)$, and pyridine (py) yielded an unprecedented $\mathrm{Ru}(\mathrm{O}) \mathrm{Co}_{3}\left(\mu_{3}-\mathrm{O}\right)_{4}(\mathrm{OAc})_{4}(\mathrm{py})_{3}$ cubane featuring an isolable, yet reactive, $\mathrm{Ru} \mathrm{V}_{-}$ oxo moiety. EPR, ENDOR, and DFT studies reveal a valence-localized $\left[\mathrm{Ru}^{\mathrm{V}}(S=1 / 2) \mathrm{Co}_{3}{ }_{3}(S=\right.$ $\left.0) \mathrm{O}_{4}\right]$ configuration and non-negligible covalency in the cubane core. Significant oxyl radical character in the $\mathrm{Ru}^{\mathrm{V}}$-oxo unit is experimentally demonstrated by radical coupling reactions between the oxo cubane and both 2,4,6-tri-tert-butylphenoxyl and trityl radicals. The oxo cubane oxidizes organic substrates and, notably, reacts with water to form an isolable $\mu$-oxo bis-cubane complex $\left[(\mathrm{py})_{3}(\mathrm{OAc})_{4} \mathrm{Co}_{3}\left(\mu_{3}-\mathrm{O}\right)_{4} \mathrm{Ru}\right]-\mathrm{O}-\left[\mathrm{RuCo}_{3}\left(\mu_{3}-\mathrm{O}\right)_{4}(\mathrm{OAc})_{4}(\mathrm{py})_{3}\right]$. Redox activity of the $\mathrm{Ru} \mathrm{V}_{-}$ oxo fragment is easily tuned by the electron-donating ability of the distal pyridyl ligand set at the Co sites demonstrating strong electronic communication throughout the entire cubane cluster. Natural bond orbital calculations reveal cooperative orbital interactions of the $\left[\mathrm{Co}_{3} \mathrm{O}_{4}\right]$ unit in supporting the $\mathrm{Ru}^{\mathrm{V}}$-oxo moiety via a strong $\pi$-electron donation.
\end{abstract}

\section{Graphical Abstract}

\footnotetext{
*Corresponding Author: tdtilley@berkeley.edu.

Supporting Information

The Supporting Information is available free of charge at https://pubs.acs.org/doi/10.1021/jacs.9b10320.

X-ray crystallographic data (CIF)

Experimental synthetic, spectroscopic, electrochemical, and computational details (PDF)

The authors declare no competing financial interest.
} 


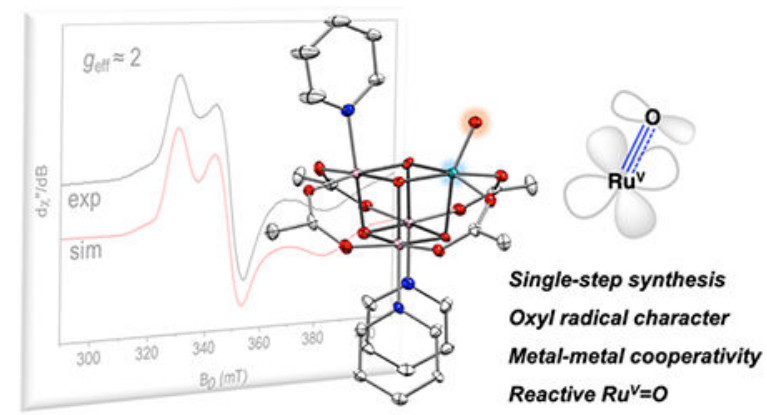

\section{INTRODUCTION}

Ruthenium is prominent among the elements associated with catalytic oxidation chemistry, with substrates ranging from organic compounds to water. ${ }^{1}$ In these oxidations, high-valent $\mathrm{Ru}^{\mathrm{V}}$-oxo intermediates are commonly invoked in substrate bond activation steps such as those involving $\mathrm{H}$ atom abstraction or $\mathrm{O}-\mathrm{O}$ bond formation..$^{2-4}$ Interestingly, several computational studies predict that the $d^{3} \mathrm{Ru}^{\mathrm{V}}$-oxo intermediates possess considerable spin density on the terminal oxo ligand and attribute their reactivity to this radical character, as in $\mathrm{O}-\mathrm{O}$ bond formation via the radical coupling of two $\mathrm{Ru}^{\mathrm{V}}$-oxo moieties. ${ }^{5-11}$ However, the reactive nature of these oxo species has generally hindered their observation, study, and experimental confirmation as intermediates, despite significant effort. ${ }^{12-16}$ Indeed, transient intermediate $\mathrm{Ru}^{\mathrm{V}}$-oxo species have only been implicated by electrochemical and spectroscopic methods. ${ }^{4,6,8,9,17-24}$ Because of their reactive nature, isolable $\mathrm{Ru}^{\mathrm{V}}$-oxo complexes are rare, and investigations into their electronic and chemical properties have been limited. ${ }^{25-28}$ The isolation and detailed investigation of $\mathrm{Ru}^{\mathrm{V}}$-oxo species should provide insight into the nature of these important chemical intermediates and the factors that influence their reactivity.

The incorporation of $\mathrm{Ru}$ into heterometal oxides or hydroxides (e.g., $\mathrm{Mn},{ }^{29} \mathrm{Co},{ }^{30,31} \mathrm{Ni}^{32}$ ) often results in superior catalytic oxidation activity, which suggests a significant influence of metal-metal cooperative effects in this chemistry. Such synergism is also observed in nature where water oxidation by the oxygen-evolving complex (OEC) in photosystem II, a $\left[\mathrm{Mn}_{4} \mathrm{CaO}_{5}\right]$ oxo cluster, involves the cooperative accumulation of redox equivalents to access formally high oxidation states and metal-oxo/oxyl species. ${ }^{33,34}$ Mechanistic analysis and characterization of relevant intermediates are quite challenging for these multimetallic systems; thus, the origins of cooperativity remain considerably unresolved. While binuclear oxo complexes of Ru, such as Meyer's "blue dimer" [ $\left[(b p y)_{2}\left(\mathrm{H}_{2} \mathrm{O}\right) \mathrm{Ru}^{\mathrm{III}} \mathrm{ORu}^{\mathrm{III}}\left(\mathrm{H}_{2} \mathrm{O}\right)\right.$ $\left.(\text { bpy })_{2}\right]^{4+}$ (bpy $=2,2^{\prime}$-bipyridine), have been extensively studied, ${ }^{35-38}$ the only examples of $\mathrm{Ru}$ incorporation into heterobimetallic oxo clusters for oxidation chemistry involve ruthenium-polyoxotung-states. ${ }^{39-41}$ The inherent complexity of these polyoxometalate frameworks makes understanding the exact roles of each metal center difficult. Thus, there is a strong need for heterometallic oxo models that can contribute to an understanding of synergistic mechanisms that enable efficient oxidations. 
Previously, this laboratory has employed the $\left[\mathrm{Co}_{3} \mathrm{O}_{4}\right]$ subcluster to support high valent $\mathrm{Co}^{\mathrm{IV}}$ and $\mathrm{Mn}^{\mathrm{IV}}$ centers in oxo-cubane complexes, ${ }^{42-44}$ and the related $\left[\mathrm{Co}_{4} \mathrm{O}_{4}\right]$ cubane has been well studied for oxygen evolution. ${ }^{44}$ Thus, it seemed that incorporation of Ru into an oxo cubane framework could perhaps generate a well-defined and reactive heterometallic oxo cubane suitable for supporting a high-valent Ru moiety (Figure 1).

This report describes the first mixed-metal $\left[\mathrm{RuCo}_{3} \mathrm{O}_{4}\right]$ oxo cubane featuring a rare $\mathrm{Ru}^{\mathrm{V}}$-oxo fragment with substantial oxyl radical character. The oxo cubane is highly active in the oxidation of various organic substrates. The reactivity of the oxo cubane with water was also examined. The synthetic versatility and simple preparation allow modulation of redox chemistry, predicted to occur at the Ru center, by tuning the donor properties of distal ligands at the Co sites. Spectroscopic and computational methods provide insight into structure, bonding, and reactivity for these new complexes.

\section{RESULTS AND DISCUSSION}

\section{Synthesis and Characterization.}

A potential route to heterobimetallic oxo cubane complexes was established with the mixedmetal oxo cubane $\mathrm{Mn}(\mathrm{OAc}) \mathrm{Co}_{3}\left(\mu_{3}-\mathrm{O}\right)_{4}(\mathrm{OAc})_{4}(\mathrm{py})_{3}$ via an oxidative assembly reaction of $\mathrm{Co}^{\mathrm{II}}(\mathrm{OAc})_{2} \cdot 4 \mathrm{H}_{2} \mathrm{O}, \mathrm{Mn}^{\mathrm{VII}} \mathrm{O}_{4}{ }^{-}$, and pyridine. ${ }^{43}$ Analogous assembly with $\mathrm{Ru}^{\mathrm{VII}} \mathrm{O}_{4}{ }^{-}$and pyridine or a para-substituted pyridine in acetonitrile afforded $\mathrm{Ru}(\mathrm{O}) \mathrm{Co}_{3}\left(\mu_{3}-\mathrm{O}\right)_{4}(\mathrm{OAc})_{4}(4-\mathrm{R}-$ py) $)_{3}$ cubanes (la-d, $\mathrm{R}=\mathrm{H}, \mathrm{CF}_{3}, \mathrm{Me}$, and $\mathrm{OMe}$, respectively) with terminal $\mathrm{Ru}-\mathrm{oxo}$ bonds in moderate yields (Scheme 1). In these reactions, a $\mathrm{Ru}^{\mathrm{VII}}$ perruthenate ion oxidizes 3 equiv of $\mathrm{Co}^{\mathrm{II}}$ to $\mathrm{Co}^{\mathrm{III}}$ to provide the $\left[\mathrm{RuCo}_{3} \mathrm{O}_{4}\right]$ cubane core. An additional equivalent of $\mathrm{RuO}_{4}{ }^{-}$ serves as a source of the terminal oxo ligand. The molecular compositions of 1a-d were verified by elemental analysis and high-resolution electrospray ionization mass spectrometry (HR-ESI-MS) (Figure S1). These complexes are stable in air when kept at room temperature. The stability and solubility of 1a-d in organic solvents such as chloroform, dichloromethane, and $o$-difluorobenzene allow further characterizations and reactivity studies.

Analysis by ${ }^{1} \mathrm{H}$ NMR spectroscopy indicated that 1a-d are $C_{S}$-symmetric (Figures S2-S5), consistent with the solid-state molecular structures (Figure 2). The bond distances within the cubane cores of $\mathbf{1 a}, \mathbf{b}$ and $\mathbf{1 d}$ are essentially identical. The $\mathrm{Co}-\mu_{3}-\mathrm{O}$ bond lengths span the range of 1.850(5)-1.904(6) $\AA$, while the $\mathrm{Ru}-\mu_{3}-\mathrm{O}$ bond lengths are longer (1.933(6)2.013(5) $\AA$ ) to accommodate the larger Ru center. The relatively short Ru1-O1 bond distances of 1.699(4)-1.719(5) $\AA$ are consistent with the presence of terminal $\mathrm{Ru}^{\mathrm{V}}{ }_{-}$oxo bonds. ${ }^{45}$ Four other $\mathrm{Ru}^{\mathrm{V}}$-oxo compounds have been isolated and structurally characterized, and the Ru-oxo bond distances are all between $1.676(6)$ and 1.756(4) $\AA^{25-28}$ Notably, the O1-Ru1-O2 and O1-Ru1-O4 angles $\left(108.8(3)^{\circ}-110.3(2)^{\circ}\right)$ indicate a Jahn-Teller distortion that likely results from a minimization of the $\pi$-antibonding character in the SOMO vide infra). A similar type of distortion occurs in a binuclear ruthenium-oxo complex supported by a cobalt-based tripodal ligand. ${ }^{28}$

The vibrational frequencies of $853-857 \mathrm{~cm}^{-1}$ for 1a-d are within the reported range for other $\mathrm{Ru}^{\mathrm{V}}$-oxo complexes, $848-900 \mathrm{~cm}^{-1},{ }^{28,45}$ and thus support the existence of $\mathrm{Ru}^{\mathrm{V}}$-oxo 
bonds in 1a-d (Figure 3 and Figure S6). The relatively strong bands below $840 \mathrm{~cm}^{-1}$ in the spectra of $\mathbf{1 b}-\mathbf{d}$ are tentatively assigned to the bending vibrations associated with parasubstituted pyridines. ${ }^{46}$ As further evidence for the peak assignments, a comparison of the IR spectra of $1 \mathrm{a}$ and the closely related, $C_{\mathrm{s}}$-symmetric $\mathrm{Mn}(\mathrm{Cl}) \mathrm{Co}_{3}\left(\mu_{3}-\mathrm{O}\right)_{4}(\mathrm{OAc})_{4}(\mathrm{py})_{3}$ cubane, ${ }^{43}$ was made (Figure S7). While there is considerable correspondence between the two spectra, there is a notable absence of the $853 \mathrm{~cm}^{-1}$ band in the spectrum of the $\left[\mathrm{MnCo}_{3} \mathrm{O}_{4}\right]$ cubane.

Continuous wave (CW) electron paramagnetic resonance (EPR) and electron nuclear double resonance (ENDOR) spectroscopies were used to interrogate the electronic structure of 1a. The CW X-band EPR spectrum of 1a exhibits a rhombic signal with $\mathrm{g}$ values of [2.032 1.9231 .740 ], diagnostic of an $S=1 / 2$ system (Figure 4a), with no resolvable ${ }^{59}$ Co hyperfine interactions (HFIs). However, coupling to the ${ }^{99} \mathrm{Ru}(I=5 / 2,13 \%)$ and ${ }^{101} \mathrm{Ru}(I=5 / 2,17 \%)$ isotopes is observed, with estimated hyperfine coupling constants of $A=\left[\begin{array}{ll}140 & 50200\end{array}\right] \mathrm{MHz}$, and is evident by broad shoulders near 320 and $395 \mathrm{mT}$. The $g$ values and HFI are similar in magnitude to the $S=1 / 2$ species of the "blue dimer" for which the unpaired spin is localized on a single Ru site. ${ }^{13}$ The relatively strong Ru HFI from the CW data suggests an $S=1 / 2$ $\mathrm{Ru}^{\mathrm{V}}$ center with three $S=0{ }^{59} \mathrm{Co}{ }^{\mathrm{III}}$ centers. This valence localized assignment (Robin-Day class I) is also supported by UV-vis-NIR measurements (Figure S8) and DFT calculations discussed in the Supporting Information (Figure SCD1).

Q-band Davies ENDOR experiments were performed to probe the contributions of ${ }^{59} \mathrm{Co}$ HFIs (Figure 4b). The peak at $\sim 25 \mathrm{MHz}$ arises from the coupling of ${ }^{59} \mathrm{Co}$ nuclei and varies slightly across the absorption envelope from $\sim 1200$ to $~ 1400 \mathrm{mT}$ (Figure S9), suggesting highly isotropic couplings. Considering the number of ${ }^{59} \mathrm{Co}$ nuclei and the symmetry of $\mathbf{1 a}$, the ${ }^{59} \mathrm{Co}$ HFIs were simulated with isotropic hyperfine coupling values of 17, 20, and 24 $\mathrm{MHz}$, which are comparable to the coupling observed in the $\mathrm{Mn}(\mathrm{OAc}) \mathrm{Co}_{3}\left(\mu_{3^{-}}\right.$ $\mathrm{O})_{4}(\mathrm{OAc})_{4}(\mathrm{py})_{3}$ cluster. $^{43}$ The peak at $\sim 55 \mathrm{MHz}$ is assigned to weak HFIs to nearby protons centered at the proton Larmor frequency $\left(v_{\mathrm{L}}=54.1 \mathrm{MHz}\right.$ at $\left.1270 \mathrm{mT}\right)$. The relatively weakyet still significant $-{ }^{59} \mathrm{Co}$ HFI from the ENDOR experiment indicates a non-negligible degree of covalency in the $\left[\mathrm{Ru}^{\mathrm{V}} \mathrm{Co}_{3} \mathrm{III}_{3} \mathrm{O}_{4}\right]$ core.

\section{Electrochemical Studies.}

Investigation of the electrochemical properties of 1a-d in $o$-difluorobenzene by cyclic voltammetry revealed a reversible one-electron oxidation and an irreversible reduction for each cluster (Figures 5a and S10). Cyclic voltammograms of $\mathbf{1 d}$ in acetonitrile and dichloromethane show redox events similar to those measured in $o$-difluorobenzene, but the potentials are more positively shifted. The effect of solvent on redox potentials is discussed in the Supporting Information (Figure S11). The observed redox activity of 1a-d displayed a strong dependence on the electron-donating property of the ligand set as evidenced by a linear correlation between the redox potentials and the conjugate acid $\mathrm{p} K_{\mathrm{a}}$ values of 4-Rpyridine in water ${ }^{47}$ (Figure 5b). The simple modulation of the donor properties of the ligand allows predictable redox tunability of the cubane clusters, such that the oxidation is facilitated by electron-donating substituents, whereas the reduction is rendered more facile by electron-withdrawing substituents. The related $\left[\mathrm{Co}_{4} \mathrm{O}_{4}\right]^{48}$ and $\left[\mathrm{Mn}_{4} \mathrm{O}_{4}\right]^{49}$ cubane series 
also exhibit similar correlations between redox potentials and ligand basicity. The observed correlations in these clusters, despite the asymmetric coordination of ligands, suggest strong electronic communication within the cubane cores.

Because of the comparatively low oxidation potential and reversibility of the redox event of 1d, chemical oxidation and isolation of the oxidized cubane were attempted. Reactions of $\mathbf{1 d}$ with various chemical oxidants yielded unidentifiable product mixtures as indicated by NMR spectroscopy. However, treatment of $\mathbf{1 d}$ with thianthrenium tetrafluoroborate in acetonitrile resulted in formation of an acetonitrile-bound complex (2-MeCN) and thianthrene oxide in nearly quantitative yields (Scheme 2). The solid-state molecular structure of 2-MeCN (Scheme 2, inset) reveals structural similarities to 1d. The Ru1-N4 distance of 2.068(11) $\AA$ is consistent with a $\mathrm{Ru}^{\mathrm{IV}}-\mathrm{NCCH}_{3}$ bond. ${ }^{50}$ Notably, the N4-Ru1-O2 and N4-Ru1-O4 bond angles span the range of 93.8(3)-95.6(3) ${ }^{\circ}$ indicating that the JahnTeller distortion is diminished, in comparison with $\mathbf{1 d}$, as is expected for a low-spin $\mathrm{d}^{4}$ configuration. The IR-active Ru-oxo band of $\mathbf{1 d}$ at $853 \mathrm{~cm}^{-1}$ is absent in 2-MeCN (Figure S12). The formation of $\mathbf{2 - M e C N}$ and thianthrene oxide suggests that the direct oxidation product of $\mathbf{1 d}$ is a reactive intermediate and acts as an $\mathrm{O}$ atom donor to thianthrene in this reaction. The question of whether the oxidation produces a $\mathrm{Ru}^{\mathrm{VI}}$ or $\mathrm{Co}^{\mathrm{IV}}$ center will be addressed in the DFT section (vide infra).

\section{Experimental Evidence for Oxyl Radical Character in the Ruv_Oxo Moiety.}

In oxidative catalysis, the $\mathrm{Ru}^{\mathrm{IV}}$-oxyl valence tautomer is implicated as an important contributor to the ground state of $\mathrm{Ru}^{\mathrm{V}}$-oxo intermediates. ${ }^{5,7,8,11,51}$ However, experimental evidence for validating these computational proposals is quite limited, ${ }^{9,52}$ and such radical properties are unprecedented in the few isolated $\mathrm{Ru}^{\mathrm{V}}$-oxo complexes. Thus, we sought to determine the reactivity of $\mathbf{1 a}$ by performing reactions with radical organic substrates.

Treatment of 1a with both 2,4,6-tri-tert-butylphenoxyl and trityl radicals in $o$ difluorobenzene afforded radical-coupled cubane complexes $\mathbf{3}$ and $\mathbf{4}$ in 95\% and $92 \%$ yields, respectively (Scheme 3). Analysis by ${ }^{1} \mathrm{H}$ NMR spectroscopy revealed that both $\mathbf{3}$ and $\mathbf{4}$ are $C_{S}$ symmetric, in agreement with the solid-state molecular structures (Scheme 3, inset). The Rul-O13 distances of 1.908(3) and 1.922(10) $\AA$ for $\mathbf{3}$ and $\mathbf{4}$ are consistent with $\mathrm{Ru}^{\mathrm{IV}}-\mu_{2}-\mathrm{OR}$ bonds. ${ }^{53}$ While most bond distances within the cubane cores remain largely unchanged from those of 1a, the Rul- $\mu_{3}-\mathrm{O} 3$ bond lengths of $\mathbf{3}$ and $\mathbf{4}$ are slightly shorter (by $\sim 0.06 \AA$ ) due to a weaker trans influence of an alkoxide versus an oxo ligand. For $\mathbf{3}$, radical coupling via the 4-position is not unexpected because the cyclohexa-2,5-dien-1-one-4-yl structure is the largest resonance contributor to the 2,4,6-tri-tert-butylphenoxyl radical. ${ }^{54,55}$ Infrared spectroscopic data corroborate the structural assignments of $\mathbf{3}$ and $\mathbf{4}$ (Figures S13 and S14).

The apparent radical nature in the $\mathrm{Ru}^{\mathrm{V}}$-oxo fragment suggests that $\mathbf{1 a}$ is a potential $\mathrm{H}$ atom abstractor. Indeed, treatment of 1a with 1 equiv of 2,4,6-tri-tert-butylphenol in $o$ difluorobenzene gave 3 in 57\% yield (91\% and 60\% conversions with respect to $1 \mathbf{a}$ and 2,4,6-tri-tert-butylphenol, by ${ }^{1} \mathrm{H}$ NMR spectroscopy), after $1 \mathrm{~h}$ at $23{ }^{\circ} \mathrm{C}$ (Scheme 3). The formation of $\mathbf{3}$ strongly indicates that $\mathrm{H}$ atom abstraction of 2,4,6-tri-tert-butylphenol by $\mathbf{1 a}$ generated the 2,4,6-tri-tert-butylphenoxyl radical in situ, which was subsequently and 
quickly trapped by 1a. The observed yield and conversions are consistent with a 1:2 mol ratio of 1a to phenol in generating two moles of phenoxyl radical. This stoichiometry suggests the formation of a formally $\mathrm{Ru}{ }^{\mathrm{III}}-\mathrm{OH}_{2}$ cubane as a byproduct. Though this species was not isolated, HR-ESI-MS analysis of the reaction mixture in acetonitrile revealed the presence of a $\left[\mathrm{Ru}^{\mathrm{III}}(\mathrm{MeCN}) \mathrm{Co}_{3}\left(\mu_{3}-\mathrm{O}\right)_{4}(\mathrm{OAc})_{4}(\mathrm{py})_{3}\right] \cdot \mathrm{H}^{+}$ion (Figure $\left.\mathrm{S} 15\right)$. These results prompted further investigations into the oxidative reactivity of $\mathbf{1 a}$.

\section{Reactivity Studies.}

Given the importance of $\mathrm{Ru}^{\mathrm{V}}$-oxo species as postulated intermediates in catalytic water oxidation, the reactivity of $\mathbf{1 a}$ with water was examined. Addition of $\leq 00$ equiv of water to solutions of 1a in dichloromethane resulted in very slow reaction, but dissolution of 1a in water at ambient temperature gave rapid gas evolution, and headspace analysis by gas chromatography identified $\mathrm{CO}_{2}$ as the primary gaseous component (Figure $\mathrm{S} 16$ ). The ${ }^{1} \mathrm{H}$ NMR spectrum of the reaction mixture after $1 \mathrm{~h}$ exhibits a new diamagnetic species, which was isolated and characterized as the $\mu$-oxo bis-cubane complex $\left[(\mathrm{py})_{3}(\mathrm{OAc})_{4} \mathrm{Co}_{3}\left(\mu_{3^{-}}\right.\right.$ $\left.\mathrm{O})_{4} \mathrm{Ru}\right]-\mathrm{O}-\left[\mathrm{RuCo}_{3}\left(\mu_{3}-\mathrm{O}\right)_{4}(\mathrm{OAc})_{4}(\mathrm{py})_{3}\right]$ (5). The chemical composition of 5 was established by elemental analysis and HR-ESI-MS (Figure S17). The solid-state structure reveals that complex 5 is $C_{2}$-symmetric (Figure 6), with Ru-O13 bond distances of 1.807(3) and $1.808(3) \AA$ and a Ru-O-Ru bond angle of $162.0(2)^{\circ}$. Compound 5 gives a well-resolved ${ }^{1} \mathrm{H}$ NMR spectrum (Figure S18), consistent with the solid-state structure and a $\mathrm{Ru}^{\mathrm{IV}}-\mathrm{O}-\mathrm{Ru}^{\mathrm{IV}}$ formulation. ${ }^{56}$

Complex 5 was isolated in 30\% yield after a reaction time of $1 \mathrm{~h}$, but this species is gradually consumed in the reaction mixture (with concomitant formation of $\mathrm{CO}_{2}$ ) such that it is completely absent after $16 \mathrm{~h}$. Additional byproducts of this reaction, observed by HRESI-MS, are $\mathrm{Co}_{4}\left(\mu_{3}-\mathrm{O}\right)_{4}(\mathrm{OAc})_{4}(\mathrm{py})_{4}$ and the $\mathrm{Ru}^{\mathrm{III}}\left(\mathrm{H}_{2} \mathrm{O}\right) \mathrm{Co}_{3} \mathrm{III}_{3} \mathrm{O}_{4}$ cubane species (Figure $\mathrm{S} 19)$. The formation of $\mathrm{CO}_{2}$ and minor quantities of the aforementioned oxo cubanes imply the presence of an oxidizing agent that decomposes organic ligands (e.g., acetate).

Attempts to identify the oxidant were made, as this might give valuable insights into the role of water in generating $\mathbf{5}$. The formation of $\mathbf{5}$ from the reaction of $\mathbf{1 a}$ with water suggests possible $\mathrm{O}$ atom transfer to $\mathrm{H}_{2} \mathrm{O}$ to produce $\mathrm{H}_{2} \mathrm{O}_{2}$, though analysis of the reaction mixture of 1a in water by ${ }^{1} \mathrm{H}$ NMR spectroscopy did not show detectable quantities of $\mathrm{H}_{2} \mathrm{O}_{2}$ (Figure S20). Nevertheless, $\mathrm{H}_{2} \mathrm{O}_{2}$ could be a reactive intermediate in this chemistry, since it rapidly reacts with compound $\mathbf{1 a}$ in organic solvents to generate a product mixture consistent with those observed in the reaction of 1a and water (by HR-ESI-MS, Figures S20 and S21). Another potential oxidant is $\mathrm{O}_{2}$, but the reaction of $1 \mathbf{a}$ with water showed no observable $\mathrm{O}_{2}$ production (monitored by a calibrated $\mathrm{O}_{2}$ sensing probe). Additionally, dissolution of $\mathbf{1 a}$ in $\mathrm{O}_{2}$ saturated water did not change the rates of decomposition of $\mathbf{1 a}$ and $\mathbf{5}$ compared with reactions in degassed water. Thus, $\mathrm{O}_{2}$ is not likely responsible for oxidation of organic ligands to $\mathrm{CO}_{2}$. Lastly, compound $\mathbf{1 a}$ itself could also be the reactive oxidant in the presence of water, as $\mathrm{H}$-bonding to terminal oxo moieties can regulate the reactivity of metal-oxo complexes by reducing the $\pi$-basicity of the oxo ligands. ${ }^{57,58}$ The weakening of the $\mathrm{Ru} \mathrm{V}_{-}$ oxo bond may enhance $\mathrm{O}$ atom transfer reactivity leading to self-oxidation and decomposition. 
Compound 1a functions as a stoichiometric oxidant toward organic substrates via $\mathrm{O}$ atom transfer and $\mathrm{C}-\mathrm{H}$ activation (Figure 7). These oxidation reactions are accompanied by concomitant reduction of the $\mathrm{Ru}^{\mathrm{V}}$-oxo to a mixture of formally $\mathrm{Ru}^{\mathrm{III}}$ cubane species, such as $\mathrm{Ru}(\mathrm{L}) \mathrm{Co}_{3}\left(\mu_{3}-\mathrm{O}\right)_{4}(\mathrm{OAc})_{4}(\mathrm{py})_{3}\left(\mathrm{~L}=\mathrm{H}_{2} \mathrm{O}\right.$, py, vacant), and compound 5 (by HR-ESI-MS, Figures S22-S26). An O atom transfer reaction from 1a to triphenylphosphine in acetonitrile resulted in quantitative formation of triphenylphosphine oxide (by ${ }^{1} \mathrm{H}$ and ${ }^{31} \mathrm{P}$ NMR spectroscopy). Analysis of an aliquot of the product mixture by HR-ESI-MS revealed the presence of two main ions containing formally $\mathrm{Ru}^{\mathrm{III}}$ species, $\left[\mathrm{Ru}(\mathrm{L}) \mathrm{Co}_{3}\left(\mu_{3}-\mathrm{O}\right)_{4}(\mathrm{OAc})_{4}(\mathrm{py})_{3}\right]$ $\cdot \mathrm{H}^{+}(\mathrm{L}=\mathrm{MeCN}$, py) (Figure S27). An EPR spectrum of the reaction mixture reveals an axial signal, as expected for a $\mathrm{Ru}^{\mathrm{III}}(S=1 / 2)$ species (Figure $\left.\mathrm{S} 28\right)$. However, attempts to isolate the $\mathrm{Ru}^{\mathrm{III}}(\mathrm{L}) \mathrm{Co}_{3}\left(\mu_{3}-\mathrm{O}\right)_{4}(\mathrm{OAc})_{4}(\mathrm{py})_{3}\left(\mathrm{~L}=\mathrm{H}_{2} \mathrm{O}, \mathrm{MeCN}\right.$, or py) cubane products of these oxidation reactions in pure form have not been successful.

The formation of $\mathbf{5}$ in organic oxidation reactions suggests a loss of the terminal oxo from the $\mathrm{Ru}$ center either via $\mathrm{O}$ atom transfer or dissociation of a subsequent aqua ligand. The resulting $\mathrm{Ru}^{\mathrm{III}}$-cubane complex may then be intercepted with an equivalent of $\mathbf{1 a}$ to form $\mathbf{5}$ (Scheme 4). Further confirmation of the proposed mechanistic step involving $\mathrm{Ru}^{\mathrm{III}}-$ cubane formation in the generation of $\mathbf{5}$ was found by treatment of 2 equiv of $\mathbf{1 a}$ with 1 equiv of triphenylphosphine in dichloromethane. This reaction afforded $\mathbf{5}$ in $28 \%$ isolated yield, along with quantitative formation of triphenylphosphine oxide (Scheme 5), confirmed by ${ }^{1} \mathrm{H}$ and ${ }^{31}$ P NMR spectroscopy and HR-ESI-MS (Figure S29). A similar scenario may also describe the formation of $\mathbf{5}$ in the reaction of $\mathbf{1 a}$ with water in which the $\mathrm{Ru}^{\mathrm{III}}$-cubane is an intermediate, presumably generated through water activation by $1 \mathrm{a}$ followed by liberation of $\mathrm{H}_{2} \mathrm{O}_{2}$ (Scheme 5). This type of dimerization has been observed in Fe-porphyrin peroxidase mimics and Fe complexes with the tetraamido macrocyclic ligand (TAML) in which formation of the $\mathrm{Fe}^{\mathrm{V}}$-oxo intermediate is followed by comproportionation with the $\mathrm{Fe}^{\mathrm{III}}$ monomer. ${ }^{59-62}$

\section{Density Functional Theory and Natural Bond Orbital Calculations.}

In agreement with the experimental data, optimization of the doublet state of 1a yielded an energy minimum in which the spin density of the unpaired electron $(\rho)$ is mostly located on $\mathrm{Ru}(\rho=0.55 a)$. In line with the magnetic measurements, the calculations predict $\rho=0.00$ for all three Co centers. The optimization of the quartet state also converged into a stable energy minimum, with most of the spin density localized over the Ru-oxo moiety ( $\rho=$ $2.56 a$ ), but this configuration is less stable than the doublet state by $6.8 \mathrm{kcal} / \mathrm{mol}$. The fully optimized geometry of the doublet state is in good agreement with the solid-state molecular structure, with root-mean-square (RMSD) and maximum (MaxD) deviations of 0.042 and $0.014 \AA$, respectively, over all metal-ligand bond distances; deviations were higher for the quartet state (RMSD $=0.067 \AA$ and $\mathrm{MaxD}=0.027 \AA$ ). In the doublet ground state, the terminal oxo ligand also contains a significant portion of the spin density $(\rho=0.38 a)$, which suggests significant oxyl character (Figure $8 \mathrm{a}$ ). Consistently, the shapes of the spin density and the SOMO are nearly identical (Figure 8b). The rest of the spin density is delocalized over the structure, with the bridging oxo ligands of the cubane core having the largest contributions (i.e., $0.01-0.02 a$ each). The antibonding nature of the SOMO accounts for the observed bending of the terminal oxo relative to $\mu_{3}-\mathrm{O}_{2}$ and $\mu_{3}-\mathrm{O}_{4}$, as seen in both the DFT 
$\left(111.1^{\circ}\right)$ and solid-state structures (108.8(3)-110.3(2) ${ }^{\circ}$; Figure 2). This bending reduces the repulsive antibonding interaction arising from the out-of-phase combination of the $\mathrm{Ru}(d)$ and $\mathrm{O}(p)$ orbitals. The analytic calculation of the frequencies by DFT shows that the stretching mode of the terminal $\mathrm{Ru}^{\mathrm{V}}$-oxo bond is IR-active (IR intensity $=372 \mathrm{~km} \mathrm{~mol}^{-1}$ ), with a predicted frequency of $882 \mathrm{~cm}^{-1}$. In line with the experiments, the calculations also show that the para-substituents of the pyridine ligands have a minor effect on the $\mathrm{Ru}-\mathrm{O}$ stretching frequency (Figure S30). The strongest shift relative to $\mathbf{1 a}$ was found for $\mathbf{1 b}$, with $\Delta v=3 \mathrm{~cm}^{-1}$ (vs $\Delta v=4 \mathrm{~cm}^{-1}$ in the experimental spectra). These calculations support a doublet ground state with a localized $\left[\mathrm{Ru}^{\mathrm{V}}(S=1 / 2) \mathrm{Co}^{\mathrm{III}} 3(S=0) \mathrm{O}_{4}\right]$ configuration and a $\mathrm{Ru}^{\mathrm{V}}-$ oxo bond with significant oxyl character.

The one-electron oxidized and reduced derivatives of $\mathbf{1 a}$ seen by cyclic voltammetry, $\mathbf{1 a}^{+}$ and $1 \mathbf{a}^{-}$, respectively, were also examined with DFT calculations. The geometry of the oxidized cubane $1 \mathbf{a}^{+}$was fully optimized, converging into a closed-shell singlet ground state with $S=0$ at all atomic centers. The triplet state also yielded an energy minimum, though it was $3.9 \mathrm{kcal} \mathrm{mol}^{-1}$ less stable than the singlet state. ${ }^{63}$ Considering the ground states of both $\mathbf{1 a}$ (doublet) and $\mathbf{1 a}^{+}$(singlet), the calculations predict an oxidation potential of $0.41 \mathrm{~V}$ vs $\mathrm{Fc} / \mathrm{Fc}^{+}$, which is similar to the experimental value $(0.53 \mathrm{~V})$. For the oxidation of the substituted cubanes, 1b-d, DFT predicts oxidation potential shifts of $+160\left(\mathrm{CF}_{3}\right),-50(\mathrm{Me})$, and $-70(\mathrm{OMe}) \mathrm{mV}$, in good agreement with the cyclic voltammetry experiments $(+100$, -50 , and $-70 \mathrm{mV}$, respectively). These data and the nature of the SOMO of 1a (Figure 8b) are consistent with the oxidation of the $\left[\mathrm{Ru}^{\mathrm{V}} \mathrm{Co}^{\mathrm{III}}{ }_{3} \mathrm{O}_{4}\right]$ valence to $\left[\mathrm{Ru}^{\mathrm{VI}} \mathrm{Co}^{\mathrm{III}} \mathrm{O}_{4}\right]$. The nature of the para substituents of the pyridine ligands has a significant influence on the energy of the SOMO in which the energy increases from $-0.1909 \mathrm{Ha}(\mathbf{1 b})$ to $-0.1817 \mathrm{Ha}$ (1d) (Figure SCD2), in line with the decreasing oxidation potentials. For $\mathbf{1 \mathbf { a } ^ { - }}$, calculations gave a triplet ground state with a $\left[\mathrm{Ru}^{\mathrm{IV}} \mathrm{Co}_{3}{ }_{3} \mathrm{O}_{4}\right]$ configuration. Upon reduction of $\mathbf{1 a}$, there is a significant elongation of the $\mathrm{Ru}-\mathrm{O}$ bond and localization of the spin density over the metal center $(1.10 a)$ and the oxo ligand $(0.76 a)$, consistent with an oxyl $\left[\mathrm{Ru}^{\mathrm{IV}}(S=1 / 2) \mathrm{O}(S\right.$ $\left.=1 / 2) \mathrm{Co}^{\mathrm{III}}{ }_{3}(S=0) \mathrm{O}_{4}\right]^{-}$configuration. These structural and electronic characteristics suggest that $\mathbf{1 a}^{-}$should be highly reactive, which may explain the observed irreversible reduction by electrochemistry. These results also suggest that the formally $\mathrm{Ru}^{\mathrm{IV}}$ and $\mathrm{Ru}{ }^{\mathrm{VI}}$ oxo species may be accessible, with the $\mathrm{Ru}-\mathrm{O}$ center acting as the reservoir for electrons in this system.

The accessibility of high-valent states of the Ru center prompted an investigation into the role of the $\left[\mathrm{Co}_{3} \mathrm{O}_{4}\right]$ framework in supporting the $\mathrm{Ru}$-oxo moiety. Specifically, natural bond orbital (NBO) calculations were carried out in the neutral $\mathbf{1 a}$ and oxidized $\mathbf{1} \mathbf{a}^{+}$, including second-order perturbation analysis to quantify the donor-acceptor interactions. The strongest interactions involve $\pi$-electron donation from the $2 p$ orbitals of the $\mu_{3}$-oxos to the $4 d$ orbitals of $\mathrm{Ru}$. These interactions are divided into two groups, cis- $\pi$ and trans- $\pi$, depending on the position of the donor $\pi$-O $(p)$ orbitals relative to the $\mathrm{Ru}$-oxo bond axis (shown in Figure 9 for 1a). In contrast with the cis- $\pi$ interactions, the trans- $\pi$ interactions have a significant contribution from the $\mu$-oxo ligand and, in one case (trans- $\pi_{2}$ ), there is a relevant contribution from a Co $3 d$ orbital. These interactions were also observed for $\mathbf{1 a}^{+}$, though with larger stabilization energies and stronger contributions from the Co $3 d$ orbitals due to the higher oxidation state of the Ru-O core (Figure SCD3). This NBO analysis shows 
that, despite the spin densities suggesting a redox-innocent character of the $\left[\mathrm{Co}_{3} \mathrm{O}_{4}\right]$ subcluster, it in fact stabilizes the $\mathrm{Ru}-\mathrm{oxyl} / \mathrm{oxo}$ moieties by strong $\pi(p \rightarrow d)$ donation, facilitating the $\mathbf{1} \rightarrow \mathbf{1}^{+}$oxidation, in line with the relatively low potentials measured in the experiments (Figure 5).

The above orbital analysis also reflects the contribution of the $\left[\mathrm{Co}_{3} \mathrm{O}_{4}\right]$ subcluster to the stabilization of the $\mathrm{Ru}^{\mathrm{IV}}$-oxyl moiety of $\mathbf{1 a}$. One key characteristic for $\mathrm{Ru}^{\mathrm{IV}}-$ oxyl intermediates implicated in oxidative catalysis is that the metal center is supported by electron-rich ligands. ${ }^{3}$ The high electron density introduced by these ligands facilitates the occupancy of the antibonding Ru-O orbitals. Similarly, the strong $\pi(\rho \rightarrow d)$ donation from the $\left[\mathrm{Co}_{3} \mathrm{O}_{4}\right]$ framework stabilizes the $\pi-\mathrm{Ru}\left(d_{x z} / d_{y z}\right)$ orbitals and promotes the population of the antibonding $\pi^{*}$-Ru-oxo $(d-p)$ orbitals, which have a strong contribution from the terminal $\mathrm{O}\left(p_{X} / p_{y}\right)$ orbitals, consistent with the oxyl character of 1a. In comparison to other transient $\mathrm{Ru}^{\mathrm{V}}$-oxo intermediates; ${ }^{4,5,9-11,24,37}$ however, 1a possesses a significantly lower spin density at the terminal oxo, which may explain why $\mathbf{1 a}$ is relatively stable and isolable. The $\left[\mathrm{Co}_{3} \mathrm{O}_{4}\right]$ subcluster appears to provide the optimal electron density to the dopant metaloxo unit enabling the isolation of the $\mathrm{Ru}^{\mathrm{V}}$-oxo $1 \mathrm{a}$ complex, with oxyl character.

\section{CONCLUDING REMARKS}

The incorporation of $\mathrm{Ru}$ into the $\left[\mathrm{Co}_{3} \mathrm{O}_{4}\right]$ subcluster has allowed isolation and full characterization of the first heterobimetallic oxo cubane containing Ru and Co ions, $\mathrm{Ru}(\mathrm{O}) \mathrm{Co}_{3}\left(\mu_{3}-\mathrm{O}\right)_{4}(\mathrm{OAc})_{4}(\mathrm{py})_{3}(\mathbf{1 a})$. This complex is also the first example of an isolable terminal metal-oxo incorporated into an oxo cubane core, the key structural motif of reactive intermediates proposed in biological and synthetic water oxidation systems. ${ }^{34,44}$ Structural, spectroscopic, and computational studies support a spin localized $\left[\mathrm{Ru}^{\mathrm{V}}(S=\right.$ $1 / 2) \mathrm{Co}^{\mathrm{III}}{ }_{3}(S=0) \mathrm{O}_{4}$ ] configuration of $\mathbf{1 a}$ with a rare $\mathrm{Ru}^{\mathrm{V}}$-oxo moiety possessing significant oxyl radical character. The radical nature of $\mathbf{1 a}$ is evidenced by the propensity of the terminal oxo to accept an electron via direct coupling with organic radicals. This remarkable experimental demonstration supports a longstanding computational proposal of oxyl radical contribution to the ground state of $\mathrm{Ru}^{\mathrm{V}}$-oxo species which may be the key intermediates in oxidative catalysis. ${ }^{3}$ In accordance with this, complex $1 \mathbf{a}$ is active in the oxidation of organic substrates. The reactivity of $\mathbf{1 a}$ toward water implicates formation of a reactive oxidizing intermediate. Though the mechanism for this reaction remains unclear, isolation of the $\mu$-oxo bis-cubane complex $\left[(\mathrm{py})_{3}(\mathrm{OAc})_{4} \mathrm{Co}_{3}\left(\mu_{3}-\mathrm{O}\right)_{4} \mathrm{Ru}^{\mathrm{IV}}\right]-\mathrm{O}-\left[\mathrm{Ru}^{\mathrm{IV}} \mathrm{Co}_{3}\left(\mu_{3}-\mathrm{O}\right)_{4}(\mathrm{OAc})_{4}(\mathrm{py})_{3}\right](\mathbf{5})$ suggests that $\mathrm{Ru}^{\mathrm{V}}$-oxo species are reactive with water. The reactivity of $\mathbf{1 a}$ established in this report will allow future mechanistic studies to analyze the role of the oxyl character in oxidation chemistry.

The strong dependence of the redox chemistry, predicted to occur at the Ru-oxo center, on the donor properties of pyridine ligands at the Co sites demonstrates a significant electronic communication throughout the entire cubane cluster. Natural bond orbital (NBO) analysis revealed a strong $\pi$-electron donation from the $\left[\mathrm{Co}_{3} \mathrm{O}_{4}\right]$ subcluster to stabilize the $\mathrm{Ru}^{\mathrm{V}}$-oxo fragment. Taken together, these results indicate that the $\left[\mathrm{Co}_{3} \mathrm{O}_{4}\right]$ unit can be regarded as an ancillary ligand that provides electronic stabilization for the $\mathrm{Ru}^{\mathrm{V}}$-oxo center. Similar donoracceptor interactions may be operative in Ru-incorporated cobalt oxides for enhanced 
oxidative reactivity, ${ }^{30,31}$ with the oxidative transformations occurring at the Ru sites while the cobalt oxides help provide an electronic environment optimally tuned for the chemical and redox steps. The strong orbital overlap between the metal and the oxide framework has been observed to promote water oxidation reactivity in Co-based spinel oxides ${ }^{64}$ and could be a critical factor for high-valent metal-oxo formation in both synthetic catalysts and natural enzymes.

\section{Supplementary Material}

Refer to Web version on PubMed Central for supplementary material.

\section{ACKNOWLEDGMENTS}

This work was primarily funded by the U.S. Department of Energy, Office of Science, Office of Basic Energy Sciences, Chemical Sciences, Geosciences, and Biosciences Division, under Contract No. DE-AC02-05CH11231. We acknowledge a National Institutes of General Medical Sciences of the National Institutes of Health grant for funding the EPR investigations, under Contract No. 1R35GM12696101. (awarded to R.D.B.), the UC Berkeley College of Chemistry NMR facility, which is supported by the National Institutes of Health under grant No. S10OD024998, and the Catalysis Facility of Lawrence Berkeley National Laboratory. This research used resources of the Advanced Light Source, which is a DOE Office of Science User Facility under contract no. DEAC02-05CH1123 1. J.A. is supported by a scholarship from the Development and Promotion of Science and Technology (DPST), Thailand. D.B. acknowledges the support from the Norwegian Research Council through the Hylleraas Centre for Quantum Molecular Sciences (Project No. 262695) and the Norwegian Metacenter for Computational Science (NOTUR; Grant No. nn4654k). We thank Prof. Craig Williams of the University of Queensland for advice on the synthesis of perruthenates. We thank Peter T. Smith for gas chromatography advice, Dr. Miao Zhang for HR-ESI-MS and IR advice, and Khetpakorn Chakarawet, Dr. Addison N. Desnoyer, Amélie Nicolay, Dr. Yang-Jin Cho, Benjamin A. Suslick, and Dr. Gavin R. Kiel for useful discussions.

\section{REFERENCES}

(1). Pagliaro M; Campestrini S; Ciriminna R Ru-Based Oxidation Catalysis. Chem. Soc. Rev 2005, 34 (10), 837-845. [PubMed: 16172673]

(2). Sala X; Maji S; Bofill R; García-Antón J; Escriche L; Llobet A Molecular Water Oxidation Mechanisms Followed by Transition Metals: State of the Art. Acc. Chem. Res 2014, 47 (2), 504516. [PubMed: 24328498]

(3). Shaffer DW; Xie Y; Concepcion JJ O-O Bond Formation in Ruthenium-Catalyzed Water Oxidation: Single-Site Nucleophilic Attack vs. O-O Radical Coupling. Chem. Soc. Rev 2017, 46 (20), 6170-6193. [PubMed: 28861558]

(4). Shing KP; Cao B; Liu Y; Lee HK; Li M. De; Phillips DL; Chang XY; Che CM Arylruthenium(III) Porphyrin-Catalyzed C-H Oxidation and Epoxidation at Room Temperature and $\left[\mathrm{Ru}^{\mathrm{V}}(\mathrm{Por})(\mathrm{O})\right.$ $(\mathrm{Ph})$ ] Intermediate by Spectroscopic Analysis and Density Functional Theory Calculations. J. Am. Chem. Soc 2018, 140 (22), 7032-7042. [PubMed: 29781605]

(5). Bianco R; Hay PJ; Hynes JT Theoretical Study of O-O Single Bond Formation in the Oxidation of Water by the Ruthenium Blue Dimer. J. Phys. Chem. A 2011, 115 (27), 8003-8016. [PubMed: 21615127]

(6). Planas N; Vigara L; Cady C; Miró P; Huang P; Hammarström L; Styring S; Leidel N; Dau H; Haumann M; Gagliardi L; Cramer CJ; Llobet A Electronic structure of oxidized complexes derived from cis-[Ru $\left.{ }^{\mathrm{II}}(\mathrm{bpy})_{2}\left(\mathrm{H}_{2} \mathrm{O}\right)_{2}\right]^{2+}$ and its photoisomerization mechanism. Inorg. Chem 2011, 50 (21), 11134-11142. [PubMed: 21992177]

(7). Yang X; Baik MH Cis, cis-[(bpy) $\left.{ }_{2} \mathrm{Ru} \mathrm{V}_{\mathrm{O}}\right]_{2} \mathrm{O}^{4+}$ Catalyzes Water Oxidation Formally via in Situ Generation of Radicaloid Ru ${ }^{I V}-O \cdot$. J. Am. Chem. Soc 2006, 128 (23), 7476-7485. [PubMed: 16756301]

(8). Duan L; Bozoglian F; Mandal S; Stewart B; Privalov T; Llobet A; Sun L A Molecular Ruthenium Catalyst with Water-Oxidation Activity Comparable to That of Photosystem II. Nat. Chem 2012, 4 (5), 418-423. [PubMed: 22522263] 
(9). Moonshiram D; Alperovich I; Concepcion JJ; Meyer TJ; Pushkar Y Experimental Demonstration of Radicaloid Character in a $\mathrm{Ru}^{\mathrm{V}}=\mathrm{O}$ Intermediate in Catalytic Water Oxidation. Proc. Natl. Acad. Sci. U. S. A 2013, 110 (10), 3765-3770. [PubMed: 23417296]

(10). Fan T; Zhan S; Ahlquist MSG Why is There a Barrier in the Coupling of Two Radicals in the Water Oxidation Reaction? ACS Catal. 2016, 6 (12), 8308-8312.

(11). Nyhlén J; Duan L; Åkermark B; Sun L; Privalov T Evolution of $\mathrm{O}_{2}$ in a Seven-Coordinate $\mathrm{Ru}^{\mathrm{IV}}$ Dimer Complex with a $[\mathrm{HOHOH}]^{-}$Bridge: A Computational Study. Angew. Chem., Int. Ed 2010, 49 (10), 1773-1777.

(12). Concepcion JJ; Tsai M-K; Muckerman JT; Meyer TJ Mechanism of Water Oxidation by SingleSite Ruthenium Complex Catalysts. J. Am. Chem. Soc 2010, 132 (5), 1545-1557. [PubMed: 20085264]

(13). Stull JA; Stich TA; Hurst JK; Britt RD Electron paramagnetic resonance analysis of a transient species formed during water oxidation catalyzed by the complex ion $\left[(b p y){ }_{2} \mathrm{Ru}_{(}\left(\mathrm{OH}_{2}\right)\right]_{2} \mathrm{O}^{4+}$. Inorg. Chem 2013, 52 (8), 4578-4586. [PubMed: 23527853]

(14). Pushkar Y; Moonshiram D; Purohit V; Yan L; Alperovich I Spectroscopic analysis of catalytic water oxidation by $\left[\mathrm{Ru}^{\mathrm{II}}\left(\text { bpy)-(tpy) } \mathrm{H}_{2} \mathrm{O}\right]^{2+}\right.$ suggests that $\mathrm{Ru}^{\mathrm{V}}=\mathrm{O}$ is not a rate-limiting intermediate. J. Am. Chem. Soc 2014, 136 (34), 11938-11945. [PubMed: 25130482]

(15). Moonshiram D; Pineda-Galvan Y; Erdman D; Palenik M; Zong R; Thummel R; Pushkar Y Uncovering the Role of Oxygen Atom Transfer in Ru-Based Catalytic Water Oxidation. J. Am. Chem. Soc 2016, 138 (48), 15605-15616. [PubMed: 27802032]

(16). Mack JBC; Walker KL; Robinson SG; Zare RN; Sigman MS; Waymouth RM; Du Bois J Mechanistic Study of Ruthenium-Catalyzed C-H Hydroxylation Reveals an Unexpected Pathway for Catalyst Arrest. J. Am. Chem. Soc 2019, 141 (2), 972-980. [PubMed: 30601662]

(17). Liu Y; Ng SM; Yiu SM; Lam WWY; Wei XG; Lau KC; Lau TC Catalytic Water Oxidation by Ruthenium(II) Quaterpyridine (qpy) Complexes: Evidence for Ruthenium(III) qpy- $N, N^{\prime \prime \prime}$ Dioxide as the Real Catalysts. Angew. Chem., Int. Ed 2014, 53 (52), 14468-14471.

(18). Murakami M; Hong D; Suenobu T; Yamaguchi S; Ogura T; Fukuzumi S Catalytic Mechanism of Water Oxidation with Single-Site Ruthenium-Heteropolytungstate Complexes. J. Am. Chem. Soc 2011, 133 (30), 11605-11613. [PubMed: 21702460]

(19). Cape JL; Lymar SV; Lightbody T; Hurst JK Characterization of Intermediary Redox States of the Water Oxidation Catalyst, $\left[\mathrm{Ru}(\mathrm{bpy})_{2}\left(\mathrm{OH}_{2}\right)\right]_{2} \mathrm{O}^{4+}$. Inorg. Chem 2009, 48 (10), 4400-4410. [PubMed: 19371067]

(20). Moonshiram D; Jurss JW; Concepcion JJ; Zakharova T; Alperovich I; Meyer TJ; Pushkar Y Structure and Electronic Configurations of the Intermediates of Water Oxidation in Blue Ruthenium Dimer Catalysis. J. Am. Chem. Soc 2012, 134 (10), 4625-4636. [PubMed: 22332726]

(21). Concepcion JJ; Jurss JW; Templeton JL; Meyer TJ One site is enough. Catalytic water oxidation by $\left[\mathrm{Ru}(\mathrm{tpy})(\mathrm{bpm})\left(\mathrm{OH}_{2}\right)\right]^{2+}$ and $\left[\mathrm{Ru}(\mathrm{tpy})(\mathrm{bpz})\left(\mathrm{OH}_{2}\right)\right]^{2+}$. J. Am. Chem. Soc 2008, 130 (49), 16462-16463. [PubMed: 19554681]

(22). Binstead RA; Chronister CW; Ni J; Hartshorn CM; Meyer TJ Mechanism of Water Oxidation by the $\mu$-Oxo Dimer $\left[(\text { bpy })_{2}\left(\mathrm{H}_{2} \mathrm{O}\right) \mathrm{Ru}(\mathrm{III}) \mathrm{ORu}(\mathrm{III})\left(\mathrm{OH}_{2}\right)(\mathrm{bpy})_{2}\right]^{4+}$. J. Am. Chem. Soc 2000, 122 (35), 8464-8473.

(23). Yamada H; Hurst JK Resonance Raman, Optical Spectroscopic, and EPR Characterization of the

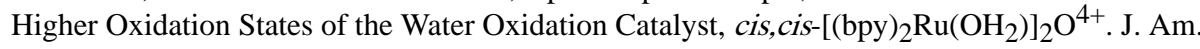
Chem. Soc 2000, 122 (22), 5303-5311.

(24). Lebedev D; Pineda-Galvan Y; Tokimaru Y; Fedorov A; Kaeffer N; Copéret C; Pushkar Y The Key $\mathrm{Ru}^{\mathrm{V}}=\mathrm{O}$ Intermediate of Site-Isolated Mononuclear Water Oxidation Catalyst Detected by in Situ X-ray Absorption Spectroscopy. J. Am. Chem. Soc 2018, 140 (1), 451-458. [PubMed: 29219306]

(25). Dengel AC; Griffith WP; O’Mahoney CA; Williams DJ A Stable Ruthenium(V) oxo complex. XRay Crystal Structure and Oxidising Properties of tetra-n-Propylammonium bis-2-Hydroxy-2Ethylbutyrato(oxo)-Ruthenate(V). J. Chem. Soc., Chem. Commun 1989, 0, 1720-1721. 
(26). Li C-K; Che C-M; Tong W-F; Tang W-T; Wong K-Y; Lai T-F Synthesis, Structure, Reactivity and Electrochemistry of cis-Dioxoruthenium-(VI) and -(V) Complexes Containing $N, N, N^{\prime}, N^{\prime}, 3,6$ Hexamethyl-3,6-Diazaoctane-1,8-Diamine. J. Chem. Soc., Dalton Trans 1992, 2109-2116.

(27). Fackler NLP; Zhang S; O'Halloran TV Stabilization of High-Valent Terminal-Oxo Complexes: Interplay of d-Orbital Occupancy and Coordination Geometry. J. Am. Chem. Soc 1996, 118 (2), 481-482.

(28). Power JM; Evertz K; Henling L; Marsh R; Schaefer WP; Labinger JA; Bercaw JE Synthesis and structural characterization of binuclear ruthenium aquo, hydroxy, and oxo complexes incorporating the anionic tripod ligand $\left[\left(\eta^{5}-\mathrm{C}_{5} \mathrm{H}_{5}\right) \mathrm{Co}-\left\{\left(\mathrm{CH}_{3} \mathrm{CH}_{2} \mathrm{O}\right)_{2} \mathrm{P}=\mathrm{O}\right\}_{3}\right]$. Inorg. Chem 1990, 29 (25), 5058-5065.

(29). Browne MP; Nolan H; Duesberg GS; Colavita PE; Lyons MEG Low-Overpotential High-Activity Mixed Manganese and Ruthenium Oxide Electrocatalysts for Oxygen Evolution Reaction in Alkaline Media. ACS Catal. 2016, 6 (4), 2408-2415.

(30). Kim Y; Park JH; Kim JG; Noh Y; Kim Y; Han H; Kim WB Ruthenium Oxide Incorporated OneDimensional Cobalt Oxide Composite Nanowires as Lithium-Oxygen Battery Cathode Catalysts. ChemCatChem 2017, 9 (18), 3554-3562.

(31). Liu X; Zeng J; Shi W; Wang J; Zhu T; Chen Y Catalytic Oxidation of Benzene over RutheniumCobalt Bimetallic Catalysts and Study of Its Mechanism. Catal. Sci. Technol 2017, 7 (1), $213-$ 221.

(32). Chala SA; Tsai M-C; Su W-N; Ibrahim KB; Duma AD; Yeh M-H; Wen C-Y; Yu C-H; Chan T-S; Dai H; Hwang B-J Site Activity and Population Engineering of NiRu-Layered Double Hydroxide Nanosheets Decorated with Silver Nanoparticles for Oxygen Evolution and Reduction Reactions. ACS Catal. 2019, 9, 117-129.

(33). Yachandra VK; Sauer K; Klein MP Manganese Cluster in Photosynthesis: Where Plants Oxidize Water to Dioxygen. Chem. Rev 1996, 96 (7), 2927-2950. [PubMed: 11848846]

(34). McEvoy JP; Brudvig GW Water-Splitting Chemistry of Photosystem II. Chem. Rev 2006, 106 (11), 4455-4483. [PubMed: 17091926]

(35). Gersten SW; Samuels GJ; Meyer TJ Catalytic Oxidation of Water by an Oxo-Bridged Ruthenium Dimer. J. Am. Chem. Soc 1982, 104 (14), 4029-4030.

(36). Gilbert JA; Eggleston DS; Murphy WR; Geselowitz DA; Gersten SW; Hodgson DJ; Meyer TJ Structure and Redox Properties of the Water-Oxidation Catalyst $\left[(b p y)_{2}\left(\mathrm{OH}_{2}\right) \mathrm{RuORu}\left(\mathrm{OH}_{2}\right)\right.$ (bpy) 2 ]. J. Am. Chem. Soc 1985, 107 (13), 3855-3864.

(37). Liu F; Concepcion JJ; Jurss JW; Cardolaccia T; Templeton JL; Meyer TJ Mechanisms of Water Oxidation from the Blue Dimer to Photosystem II. Inorg. Chem 2008, 47 (6), 1727-1752. [PubMed: 18330966]

(38). Blakemore JD; Crabtree RH; Brudvig GW Molecular Catalysts for Water Oxidation. Chem. Rev 2015, 115 (23), 12974-13005. [PubMed: 26151088]

(39). Geletii YV; Botar B; Kögerler P; Hillesheim DA; Musaev DG; Hill CL An All-Inorganic, Stable, and Highly Active Tetraruthenium Homogeneous Catalyst for Water Oxidation. Angew. Chem 2008, 120 (21), 3960-3963.

(40). Liu YP; Zhao SF; Guo SX; Bond AM; Zhang J; Zhu G; Hill CL; Geletii YV Electrooxidation of Ethanol and Methanol Using the Molecular Catalyst $\left[\left\{\mathrm{Ru}_{4} \mathrm{O}_{4}(\mathrm{OH})_{2}\left(\mathrm{H}_{2} \mathrm{O}\right)_{4}\right\}\left(\gamma-\mathrm{SiW}_{10} \mathrm{O}_{36}\right)_{2}\right]^{10-}$. J. Am. Chem. Soc 2016, 138 (8), 2617-2628. [PubMed: 26848832]

(41). Sartorel A; Carraro M; Scorrano G; Zorzi RD; Geremia S; McDaniel ND; Bernhard S; Bonchio M Polyoxometalate Embedding of a Tetraruthenium(IV)-oxo-core by Template-Directed Metalation of $\left[\gamma-\mathrm{SiW}_{10} \mathrm{O}_{36}\right]^{8-}$ : A Totally Inorganic Oxygen Evolving Catalyst. J. Am. Chem. Soc 2008, 130 (iv), 5006-5007. [PubMed: 18345628]

(42). Ullman AM; Liu Y; Huynh M; Bediako DK; Wang H; Anderson BL; Powers DC; Breen JJ; Abruña HD; Nocera DG Water Oxidation Catalysis by $\mathrm{Co}(\mathrm{II})$ Impurities in Co(III) ${ }_{4} \mathrm{O}_{4}$ Cubanes. J. Am. Chem. Soc 2014, 136 (50), 17681-17688. [PubMed: 25407218]

(43). Nguyen AI; Suess DLM; Darago LE; Oyala PH; Levine DS; Ziegler MS; Britt RD; Tilley TD Manganese-Cobalt Oxido Cubanes Relevant to Manganese-Doped Water Oxidation Catalysts. J. Am. Chem. Soc 2017, 139 (15), 5579-5587. [PubMed: 28347135] 
(44). Nguyen AI; Ziegler MS; Oña-Burgos P; Sturzbecher-Hohne M; Kim W; Bellone DE; Tilley TD Mechanistic Investigations of Water Oxidation by a Molecular Cobalt Oxide Analogue: Evidence for a Highly Oxidized Intermediate and Exclusive Terminal Oxo Participation. J. Am. Chem. Soc 2015, 137 (40), 12865-12872. [PubMed: 26390993]

(45). Ishizuka T; Kotani H; Kojima T Characteristics and Reactivity of Ruthenium-Oxo Complexes. Dalt. Trans 2016, 45 (42), 16727-16750.

(46). Katritzky AR The Infrared Spectra of Heteroaromatic Compounds. Q. Rev., Chem. Soc 1959, 13, 353-373.

(47). CRC Handbook of Chemistry and Physics, 87th ed.; Lide DR, Ed.; CRC Press: Boca Raton, FL, 2006.

(48). Nguyen AI; Wang J; Levine DS; Ziegler MS; Tilley TD Synthetic Control and Empirical Prediction of Redox Potentials for $\mathrm{Co}_{4} \mathrm{O}_{4}$ Cubanes over a 1.4 V Range: Implications for Catalyst Design and Evaluation of High-Valent Intermediates in Water Oxidation. Chem. Sci 2017, 8, 4274-4284. [PubMed: 29081963]

(49). Lee HB; Agapie T Redox Tuning via Ligand-Induced Geometric Distortions at a $\mathrm{YMn}_{3} \mathrm{O}_{4}$ Cubane Model of the Biological Oxygen Evolving Complex. Inorg. Chem 2019, DOI: 10.1021/ acs.inorgchem.9b00510.

(50). Patra SK; Majumdar M; Bera JK Ligand Assisted Homolytic Cleavage of the Ru-Ru Single Bond in $\left[\mathrm{Ru}_{2}(\mathrm{CO})_{4}\right]^{2+}$ Core and the Chemical Consequence. J. Organomet. Chem 2006, 691 (22), 4779-4787.

(51). Vigara L; Ertem MZ; Planas N; Bozoglian F; Leidel N; Dau H; Haumann M; Gagliardi L; Cramer CJ; Llobet A Experimental and Quantum Chemical Characterization of the Water Oxidation Cycle Catalysed by $\left[\mathrm{Ru}^{\mathrm{II}}(\mathrm{damp})(\mathrm{bpy})\left(\mathrm{H}_{2} \mathrm{O}\right)\right]^{2+}$. Chem. Sci 2012, 3 (8), 2576-2586.

(52). Shimoyama Y; Kojima T Metal-Oxyl Species and Their Possible Roles in Chemical Oxidations. Inorg. Chem 2019, 58, 9517-9542. [PubMed: 31304743]

(53). Chen SW; Villanneau R; Li Y; Chamoreau LM; Boubekeur K; Thouvenot R; Gouzerh P; Proust A Hydrothermal synthesis and structural characterization of the high-valent rutheniumcontaining polyoxoanion $\left[\left\{\mathrm{PW}_{11} \mathrm{O}_{39}\right\}_{2}\left\{(\mathrm{HO}) \mathrm{Ru}^{\mathrm{IV}}-\mathrm{O}-\mathrm{Ru}^{\mathrm{IV}}(\mathrm{OH})\right\}\right]^{10-}$. Eur. J. Inorg. Chem 2008, No. 13, 2137-2142.

(54). Manner VW; Markle TF; Freudenthal JH; Roth JP; Mayer JM The First Crystal Structure of a Monomeric Phenoxyl Radical: 2,4,6-tri-tert-Butylphenoxyl Radical. Chem. Commun 2008, 246 (2), 256-258.

(55). Cook CD; Woodworth RC Oxidation of Hindered Phenols. II. The 2,4,6-Tri-t-butylphenoxy Radical. J. Am. Chem. Soc 1953, 75 (24), 6242-6244.

(56). Mathieson AM; Mellor DP; Stephenson NC The crystal structure of potassium hydroxychlororuthenate, K4Ru2C110O.H2O. Acta Crystallogr. 1952, 5 (2), 185-186.

(57). Borovik AS Bioinspired Hydrogen Bond Motifs in Ligand Design: The Role of Noncovalent Interactions in Metal Ion Mediated Activation of Dioxygen. Acc. Chem. Res 2005, 38 (1), 54-61. [PubMed: 15654737]

(58). MacBeth CE; Gupta R; Mitchell-Koch KR; Young VG; Lushington GH; Thompson WH; Hendrich MP; Borovik AS Utilization of Hydrogen Bonds to Stabilize M-O(H) Units: Synthesis and Properties of Monomeric Iron and Manganese Complexes with Terminal Oxo and Hydroxo Ligands. J. Am. Chem. Soc 2004, 126 (8), 2556-2567. [PubMed: 14982465]

(59). Collins TJ; Ryabov AD Targeting of High-Valent Iron-TAML Activators at Hydrocarbons and beyond. Chem. Rev 2017, 117 (13), 9140-9162. [PubMed: 28488444]

(60). Woo FS; Cahiwat-Alquiza M; Kelly HC Iron Porphyrin Models of Peroxidase Enzymes: Catalytic Activity, Regeneration, and Oxidative Degradation of Mesoferriheme. Inorg. Chem 1990, 29 (23), 4718-4723.

(61). Chin DH; Del Gaudio J; La Mar GN; Balch AL Detection and Characterization of the LongPostulated Fe-OO-Fe Intermediate in the Autoxidation of Ferrous Porphyrins. J. Am. Chem. Soc 1977, 99 (16), 5486-5488. [PubMed: 886109]

(62). Kundu S; Van Kirk Thompson J; Ryabov AD; Collins TJ On the Reactivity of Mononuclear Iron(V)oxo Complexes. J. Am. Chem. Soc 2011, 133 (46), 18546-18549. [PubMed: 21985217] 
(63). Sala X; Ertem MZ; Vigara L; Todorova TK; Chen W; Rocha RC; Aquilante F; Cramer CJ; Gagliardi L; Llobet A The cis- $\left[\mathrm{Ru}^{\mathrm{II}}(\mathrm{bpy})_{2}\left(\mathrm{H}_{2} \mathrm{O}\right)_{2}\right]^{2+}$ water-oxidation catalyst revisited. Angew. Chem., Int. Ed 2010, 49 (42), 7745-7747.

(64). Sun S; Sun Y; Zhou Y; Xi S; Ren X; Huang B; Liao H; Wang LP; Du Y; Xu Z Shifting Oxygen Charge Towards Octahedral Metal: a Way to Promote Water Oxidation on Cobalt Spinel Oxides. Angew. Chem., Int. Ed 2019, 58, 6042-6047. 


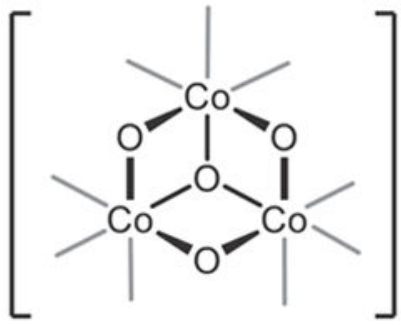

$\left[\mathrm{Co}_{3} \mathrm{O}_{4}\right]$ unit

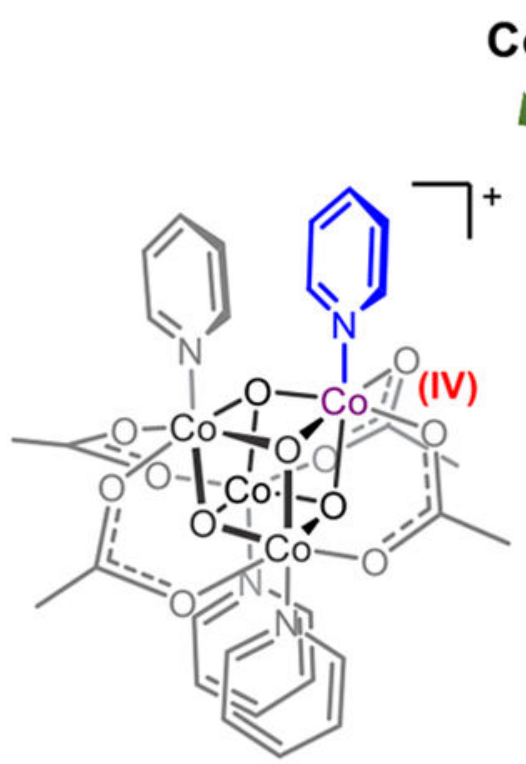

Nocera and co-workers $\left[\mathrm{Co}_{4} \mathrm{O}_{4}\right]$
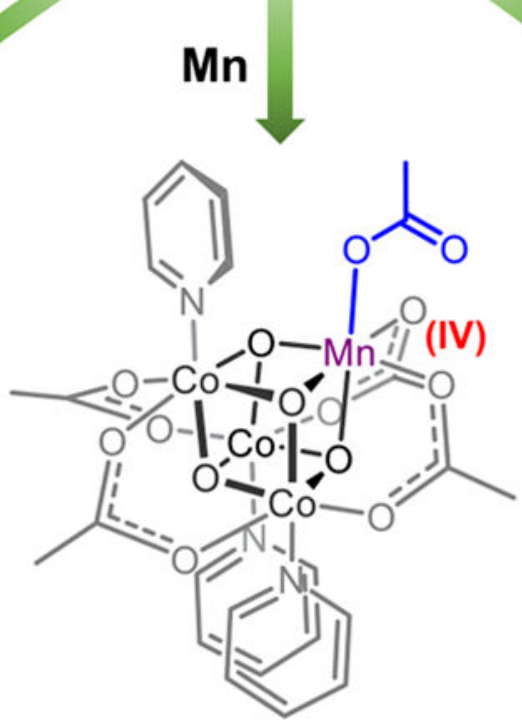

Tilley and co-workers $\left[\mathrm{MnC}_{3} \mathrm{O}_{4}\right]$
$\mathbf{R u}$

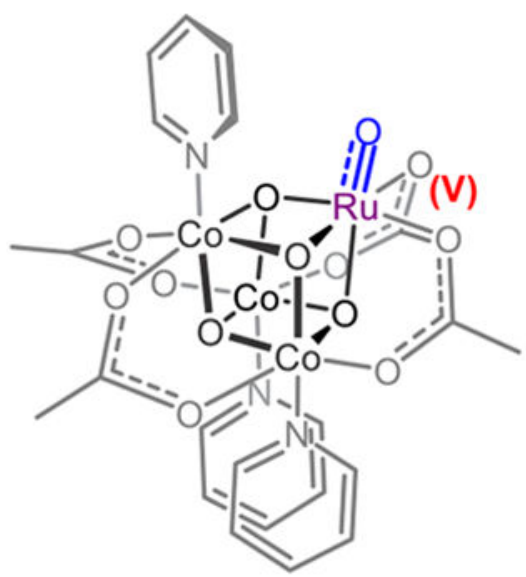

this report $\left[\mathrm{RuCO}_{3} \mathrm{O}_{4}\right]$

Figure 1.

High-valent $\mathrm{Co}^{\mathrm{IV}}, \mathrm{Mn}^{\mathrm{IV}}$, and $\mathrm{Ru}^{\mathrm{V}}$ centers supported by a $\left[\mathrm{Co}_{3} \mathrm{O}_{4}\right]$ subcluster. 

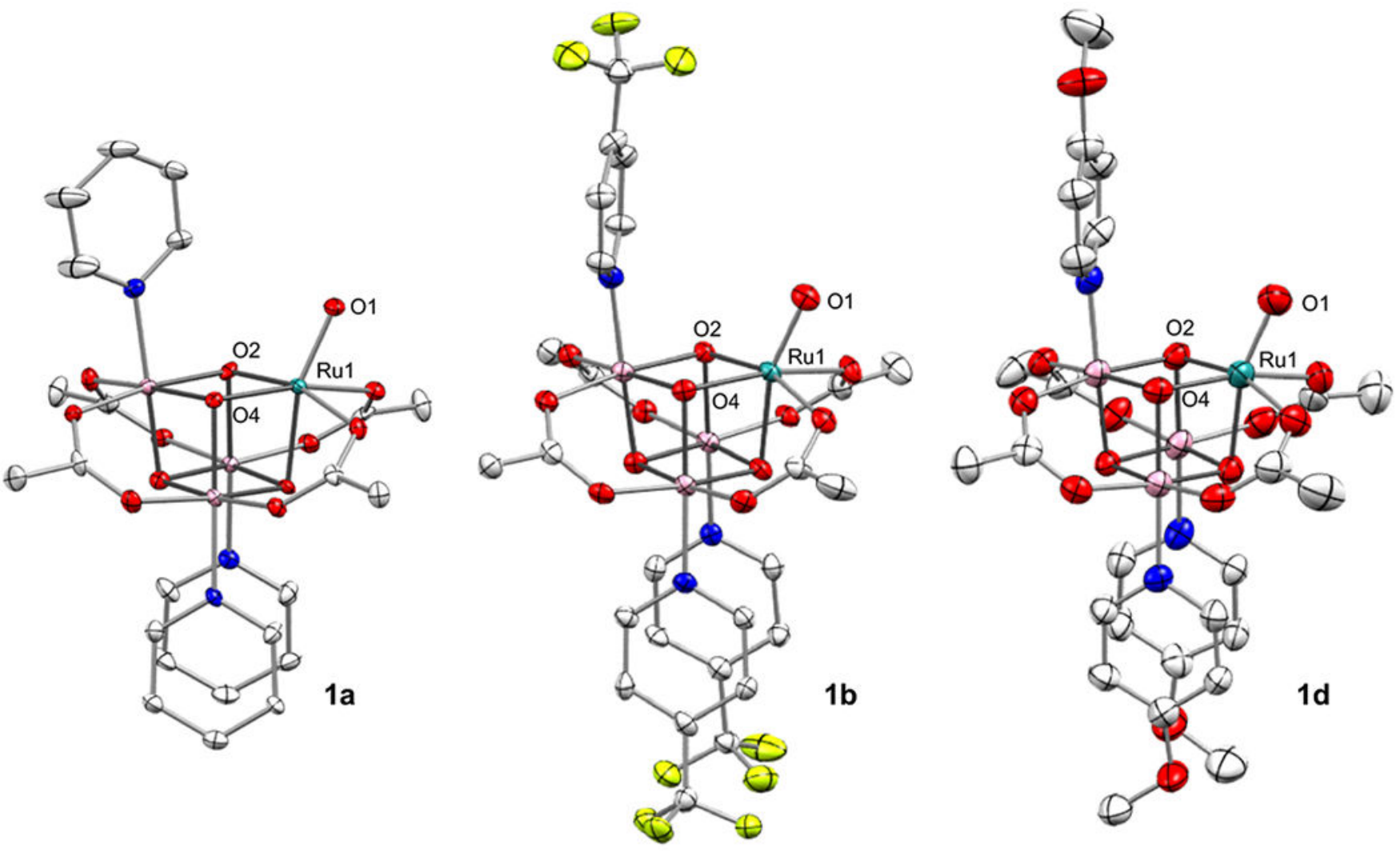

Figure 2.

Solid-state molecular structures of $\mathrm{Ru}(\mathrm{O}) \mathrm{Co}_{3}\left(\mu_{3}-\mathrm{O}\right)_{4}(\mathrm{OAc})_{4}(4-\mathrm{R}-\mathrm{py})_{3}$ cubanes, $\mathrm{R}=\mathrm{H}(\mathbf{1 a})$, $\mathrm{CF}_{3}(\mathbf{1 b})$, and $\mathrm{OMe}(\mathbf{1 d})$. An additional molecule of $\mathbf{1 a}$ in the asymmetric unit, solvent molecules, and hydrogen atoms are omitted for clarity. Thermal ellipsoids are shown at 50\% probability. 


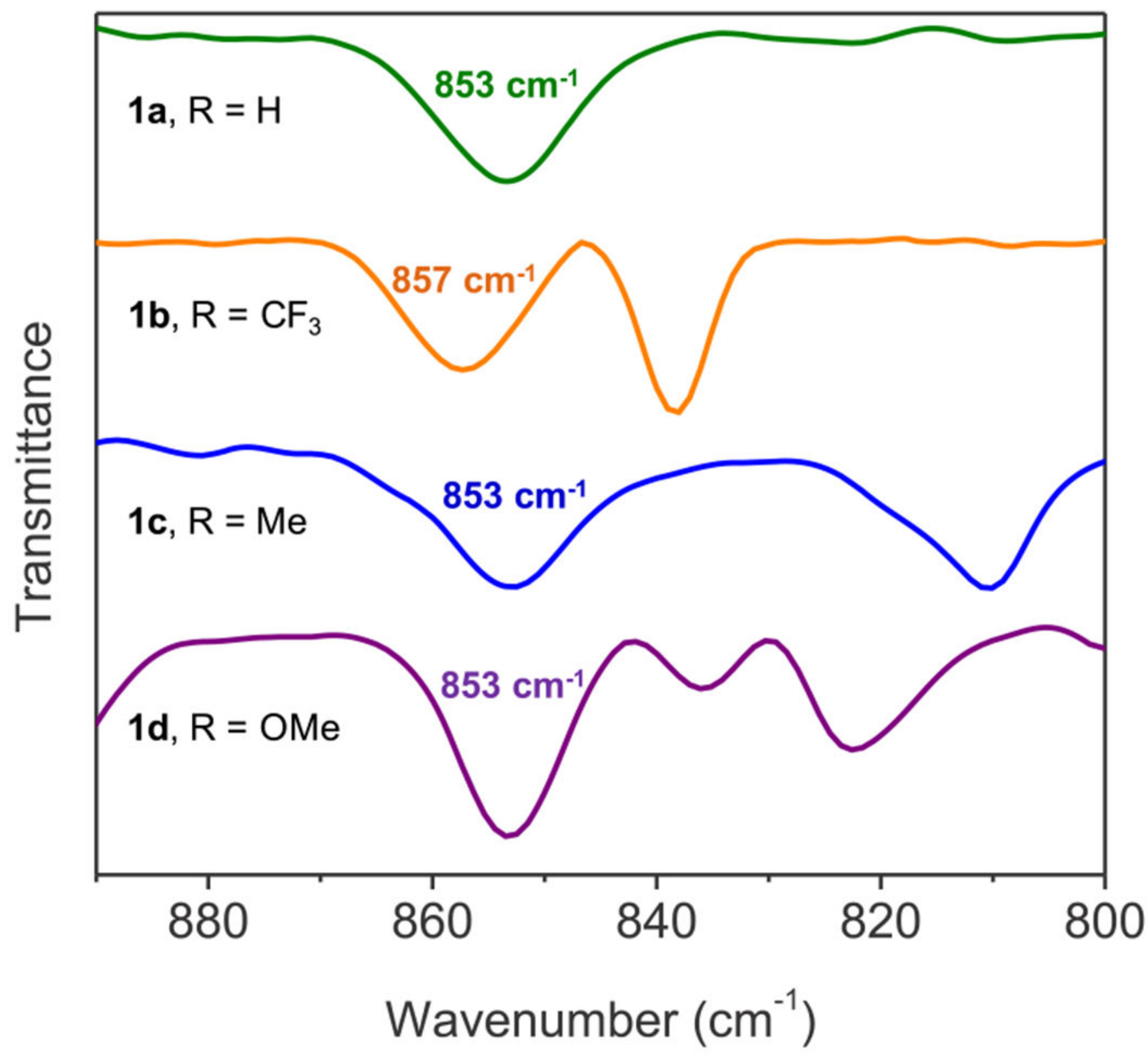

Figure 3.

Partial solution-state IR spectra of $\mathbf{1 a - d}$ in dichloromethane demonstrating intense $\mathrm{Ru}^{\mathrm{V}}$-oxo absorptions. 
a)

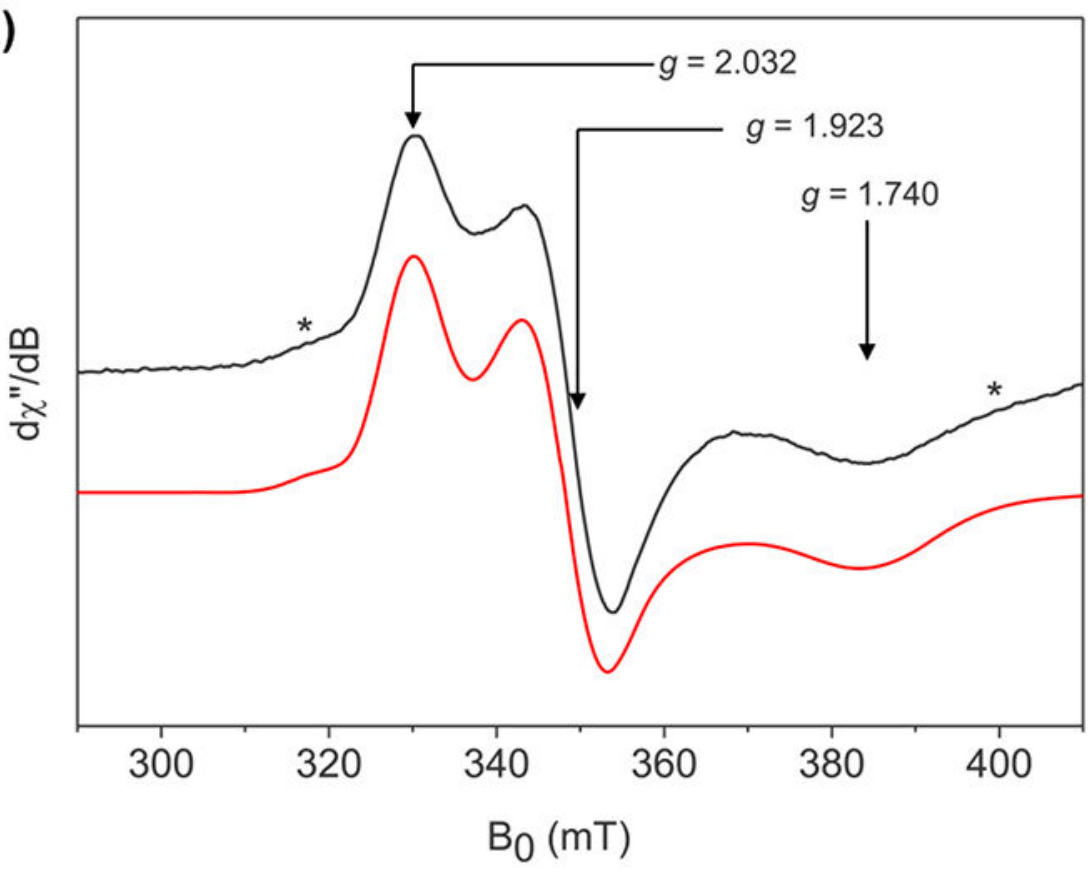

b)

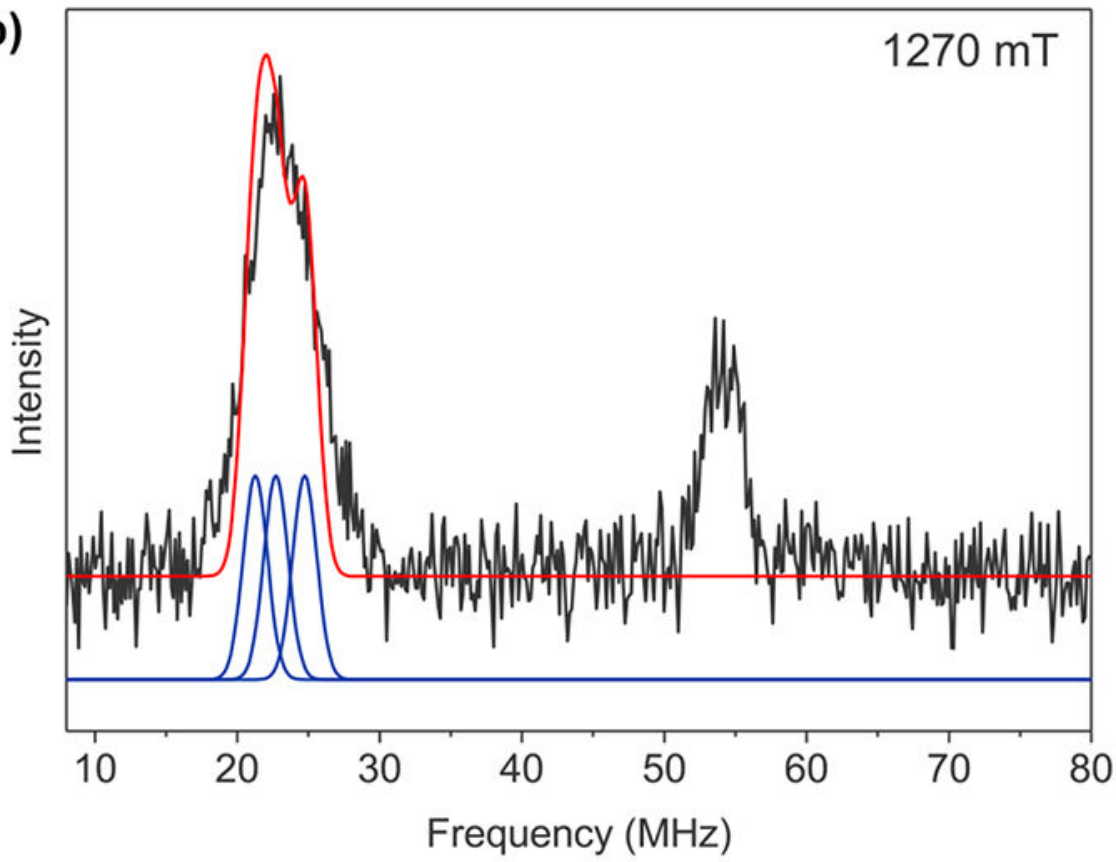

Figure 4.

(a) EPR spectrum (black) of $\mathbf{1 a}$ taken at $20 \mathrm{~K}$ and simulation of the data (red) using $g$-values of [2.032 1.923 1.740]. Simulations include contributions of natural abundance ${ }^{99} \mathrm{Ru}(I=$ $5 / 2,13 \%)$ and ${ }^{101} \mathrm{Ru}(I=5 / 2,17 \%)$ isotopes (*). (b) Davies ENDOR spectrum of $\mathbf{1 a}$ recorded at $6 \mathrm{~K}$ (black). The peak at $\sim 23 \mathrm{MHz}$ can be simulated (red) using three isotropic ${ }^{59} \mathrm{Co}$ centers with hyperfine couplings of 17,20 , and $24 \mathrm{MHz}$, individual components shown in blue. 

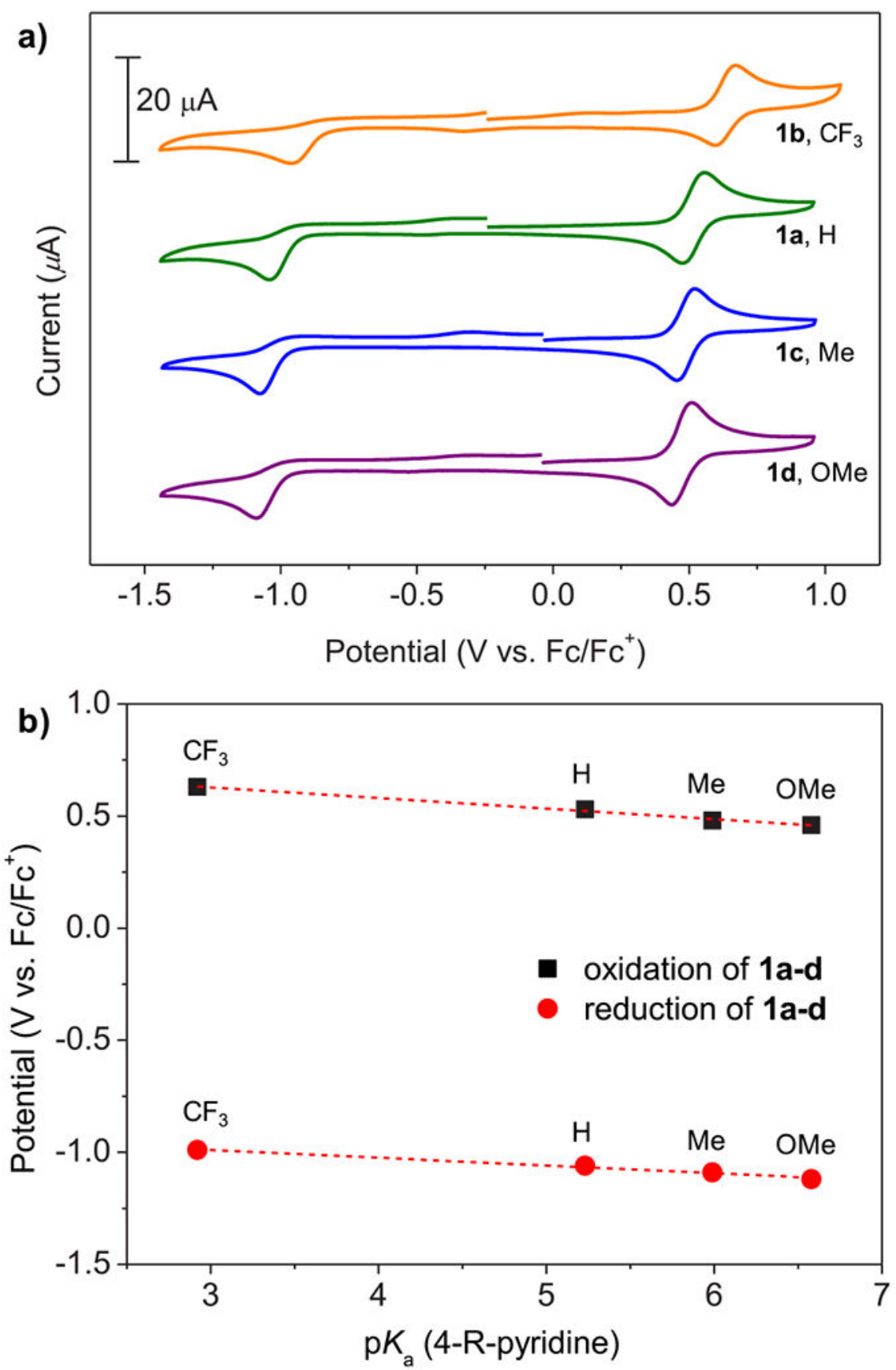

Figure 5.

(a) Cyclic voltammograms of $\mathbf{1 a}-\mathbf{d}$ in $o$-difluorobenzene $\left(v=100 \mathrm{mV} / \mathrm{s}, 0.1 \mathrm{M}\left[{ }^{\mathrm{n}} \mathrm{Bu}_{4} \mathrm{~N}^{\mathrm{P}} \mathrm{PF}_{6}\right.\right.$ electrolyte). Oxidation potentials are $0.53,0.63,0.48$, and $0.46 \mathrm{~V} \mathrm{vs} \mathrm{Fc} / \mathrm{Fc}^{+}$, and reduction potentials are $-1.06,-0.99,-1.09$, and $-1.12 \mathrm{~V} \mathrm{vs} \mathrm{Fc} / \mathrm{Fc}^{+}$for $\mathbf{1 a}-\mathbf{d}$, respectively. (b) Plot of redox potentials of 1a-d vs conjugate acid $\mathrm{p} K_{\mathrm{a}}$ values of 4-R-pyridine with linear regression $\left(\mathrm{R}^{2}=0.9940\right.$ for oxidation and $\mathrm{R}^{2}=0.9884$ for reduction $)$. 


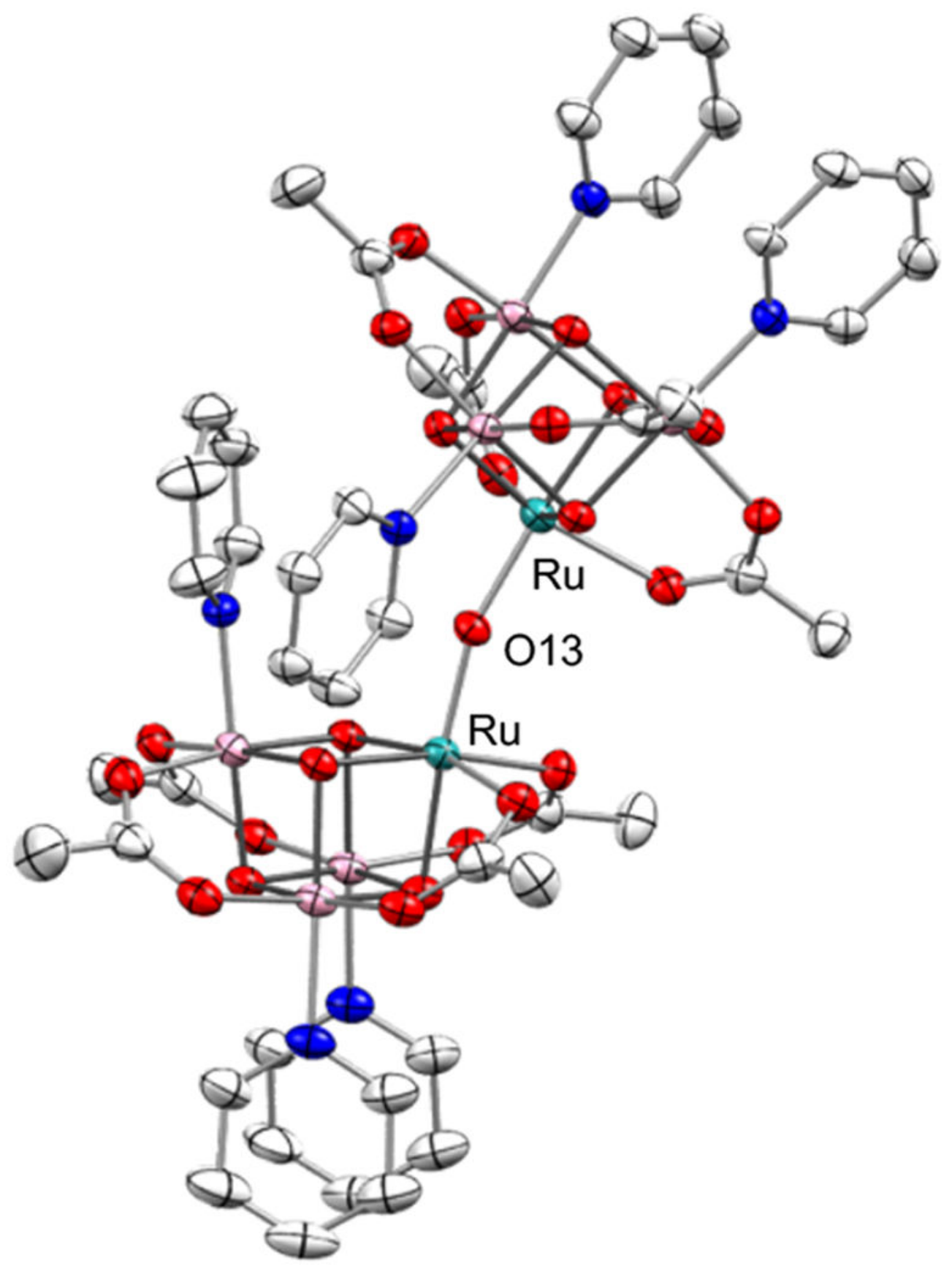

Figure 6.

Solid-state structure of $\mathbf{5}$. Solvent molecules and hydrogen atoms are omitted for clarity. Thermal ellipsoids are shown at $50 \%$ probability. 


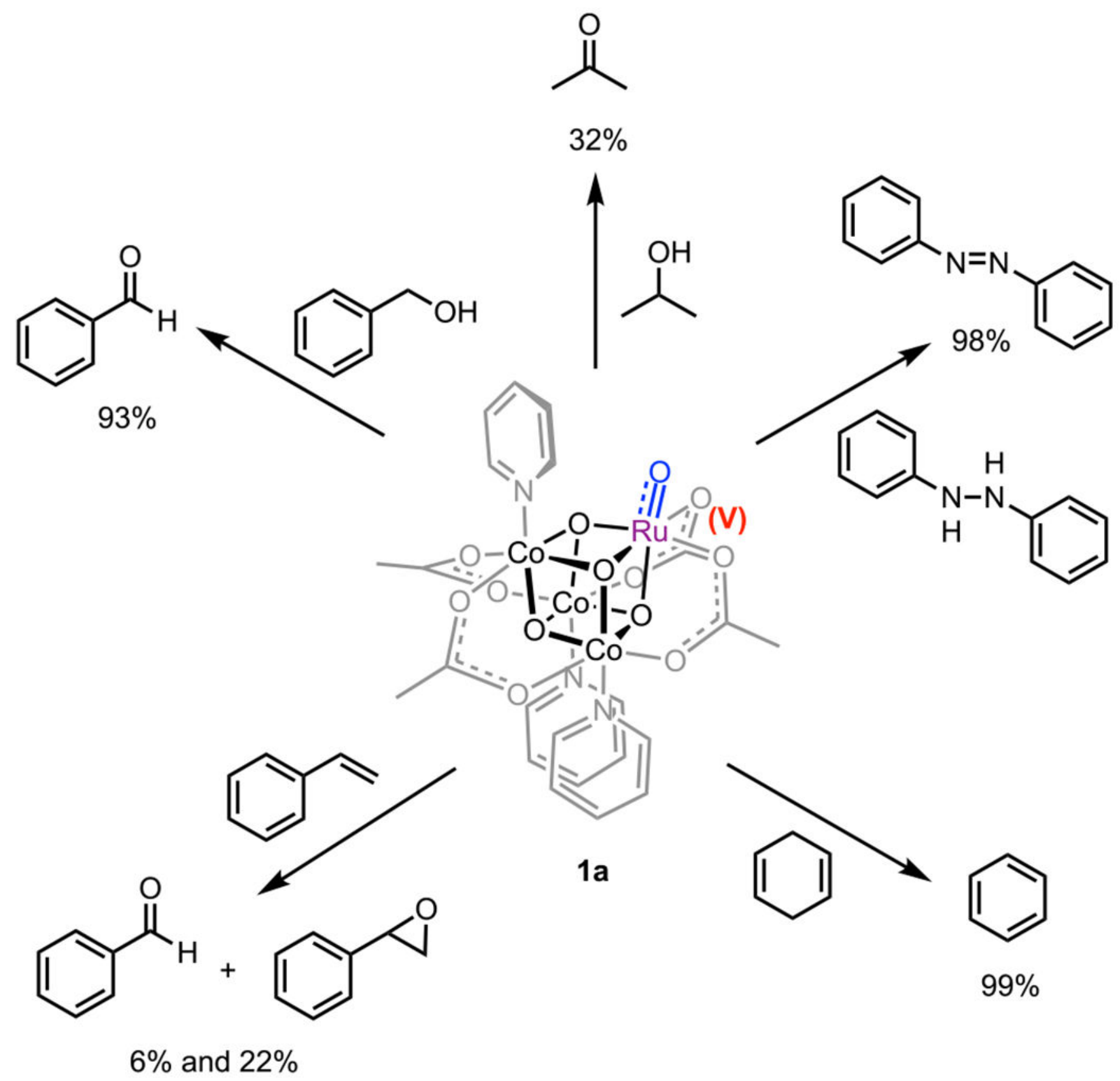

Figure 7.

Oxidation reactions of $\mathrm{Ru}(\mathrm{O}) \mathrm{Co}_{3}\left(\mu_{3}-\mathrm{O}\right)_{4}(\mathrm{OAc})_{4}(\mathrm{py})_{3}(\mathbf{1 a})$ with organic substrates in $\mathrm{CDCl}_{3}$ at $23{ }^{\circ} \mathrm{C}$ under an atmosphere of $\mathrm{N}_{2}$. Yields were determined per 1 equiv of $\mathbf{1 a}$ by ${ }^{1} \mathrm{H}$ NMR analysis at $24 \mathrm{~h}$ using tetrakis(trimethylsilyl)silane as an internal standard. Reaction mixtures were heated to $50{ }^{\circ} \mathrm{C}$ for isopropyl alcohol and styrene. 
a)

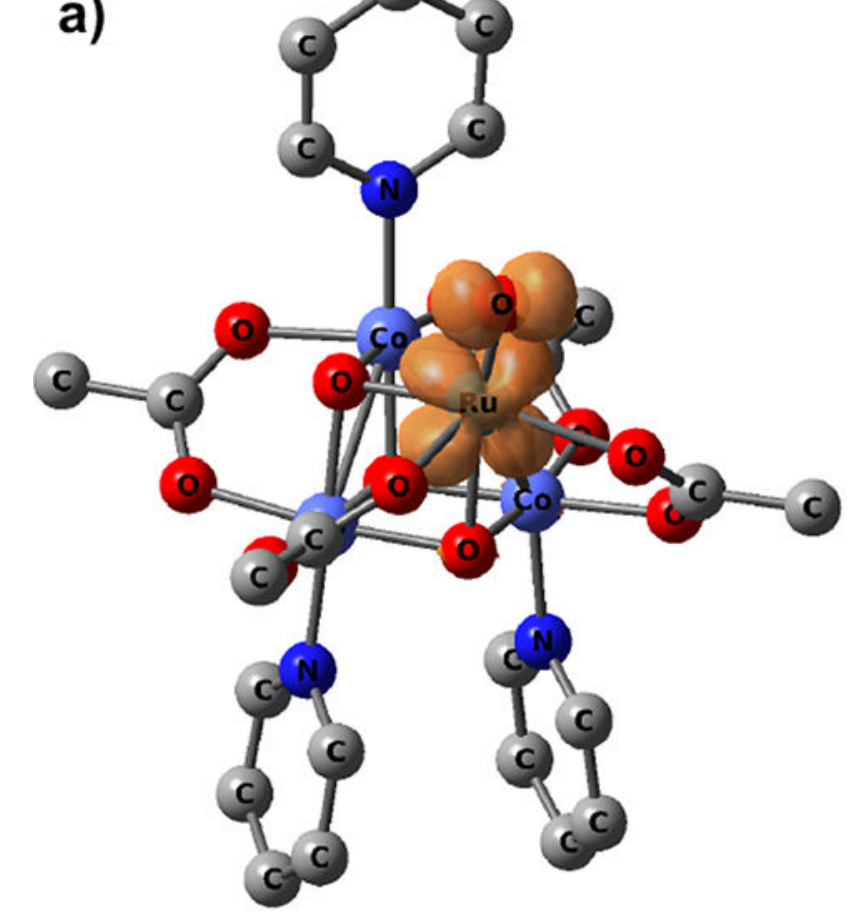

b)

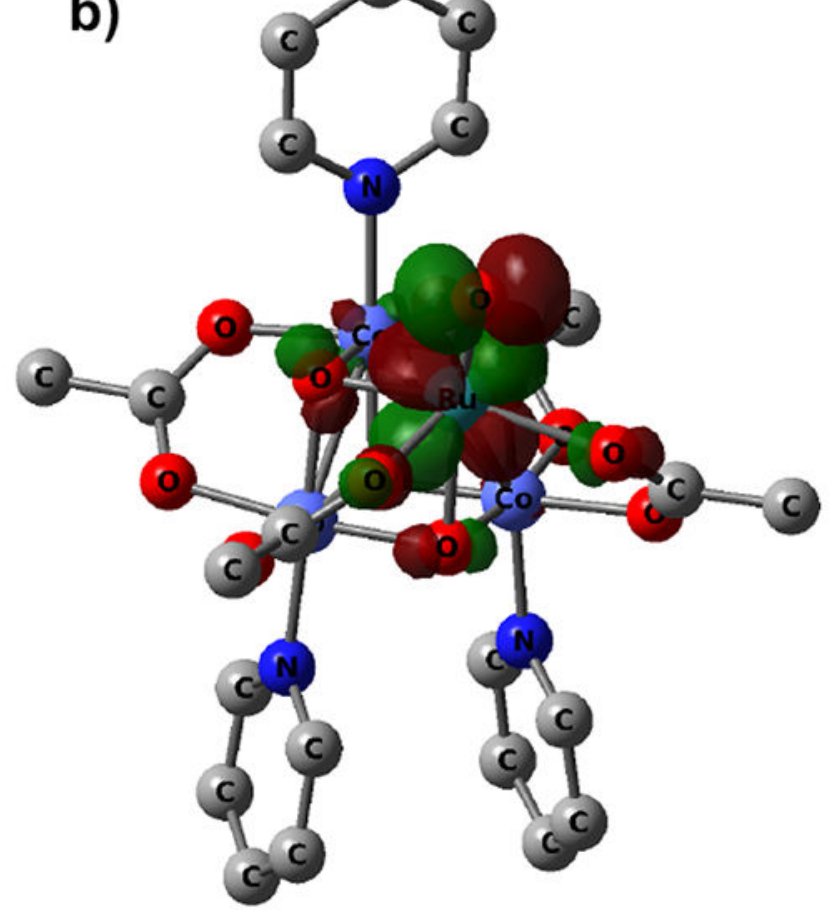

Figure 8.

(a) Spin density $(\rho(\mathrm{Ru}: \mathrm{O})=0.55: 0.38 a)$ and (b) SOMO of 1a for the doublet ground state. The SOMO is a combination of $\operatorname{Ru}(d)$ and $\pi$-oxo $(p)$ orbitals. Isovalues are $0.007(\rho)$ and 0.05 (SOMO). 


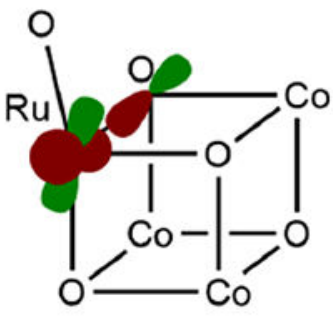

cis- $\pi_{1}$

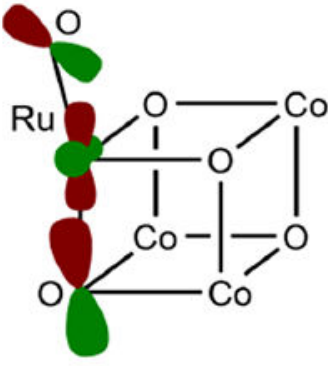

trans $-\pi_{1}$

Figure 9.
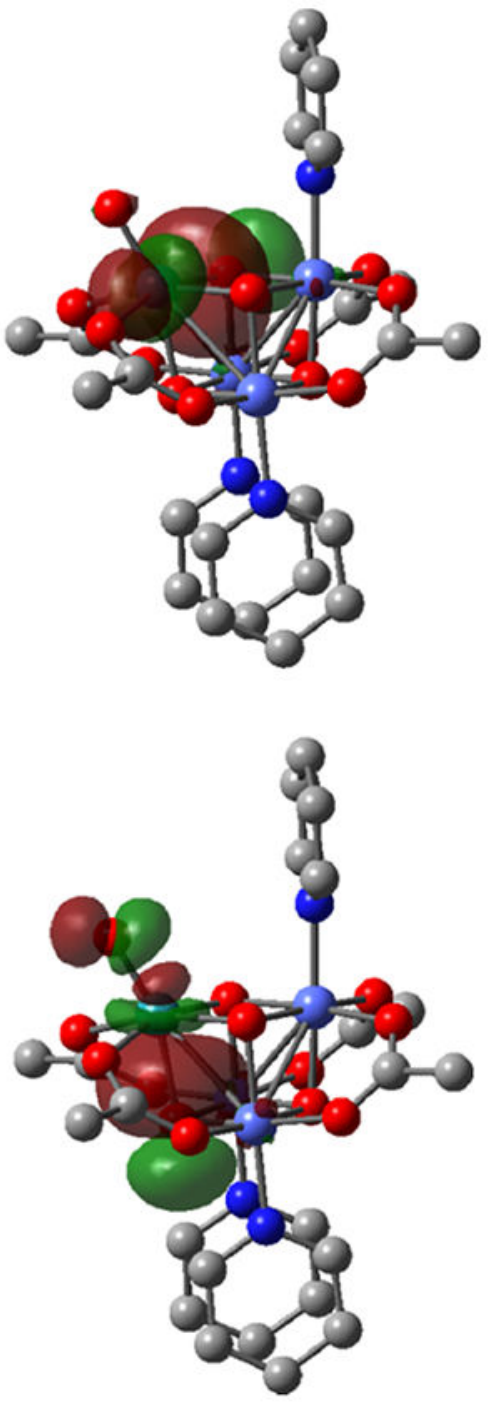

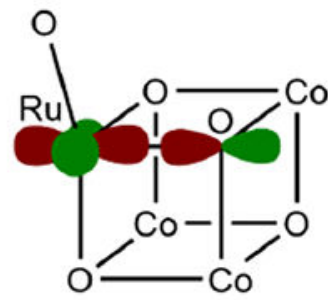

cis $-\pi_{2}$
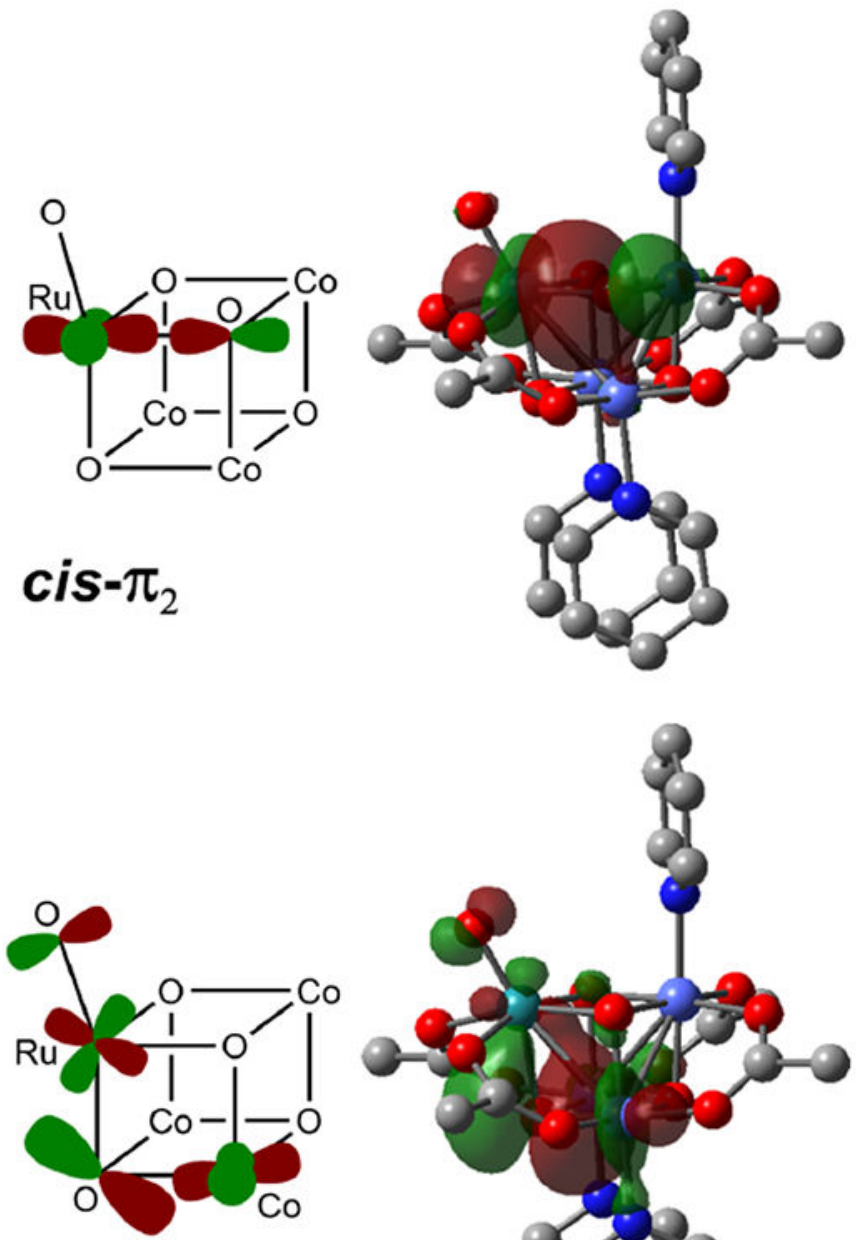

trans $-\pi_{2}$

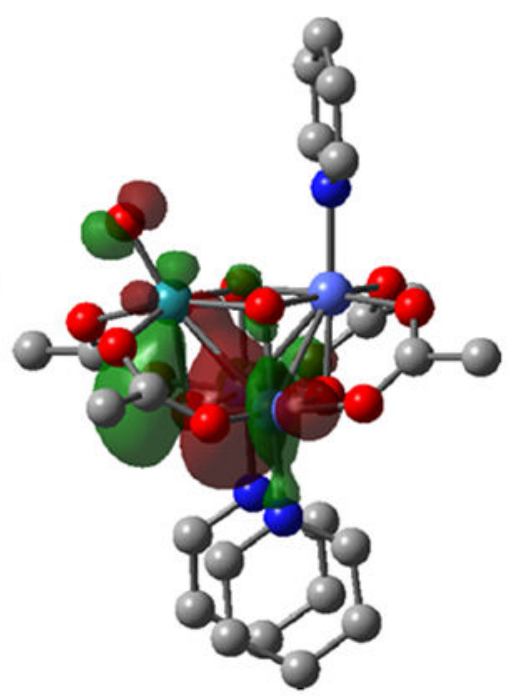

Selected NLMOs (natural localized molecular orbitals) associated with the covalent interactions between the $\left[\mathrm{Co}_{3} \mathrm{O}_{4}\right]$ (donor) and $\mathrm{Ru}-\mathrm{Oxo}$ (acceptor) moieties. Orbitals were plotted for 1a, with a surface isovalue of 0.02 . 


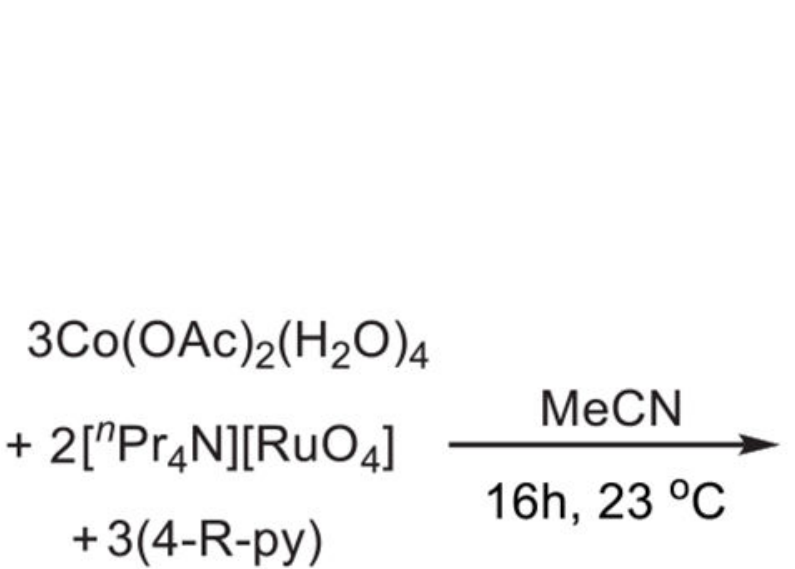

Scheme 1.

Synthesis of $\left[\mathrm{RuCo}_{3} \mathrm{O}_{4}\right]$ Oxo Cubanes

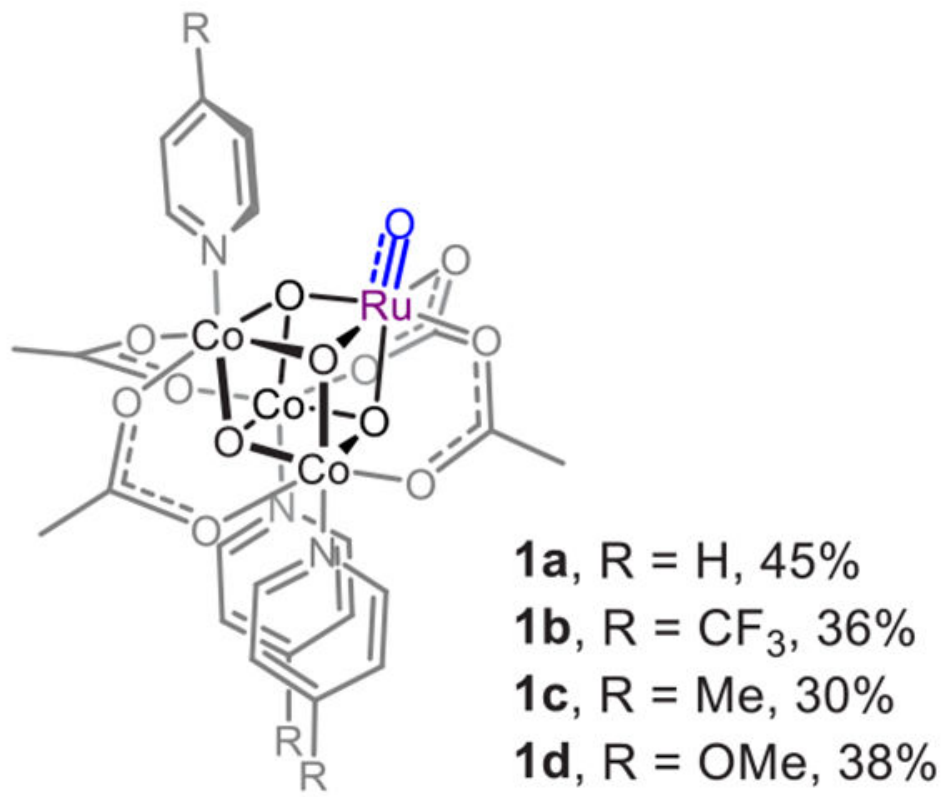



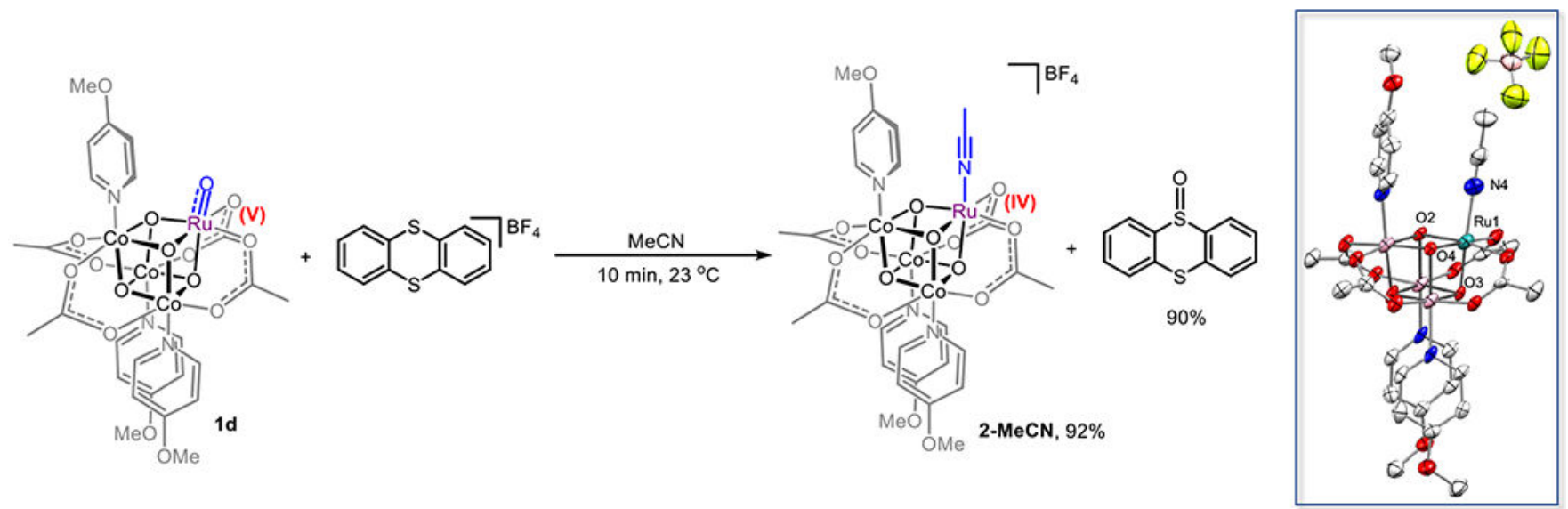

Scheme 2. Synthesis of 2-MeCN ${ }^{a}$

Inset: Solid-state molecular structure of 2-MeCN. Solvents and hydrogen atoms are omitted for clarity. Thermal ellipsoids are shown at 50\% probability. 


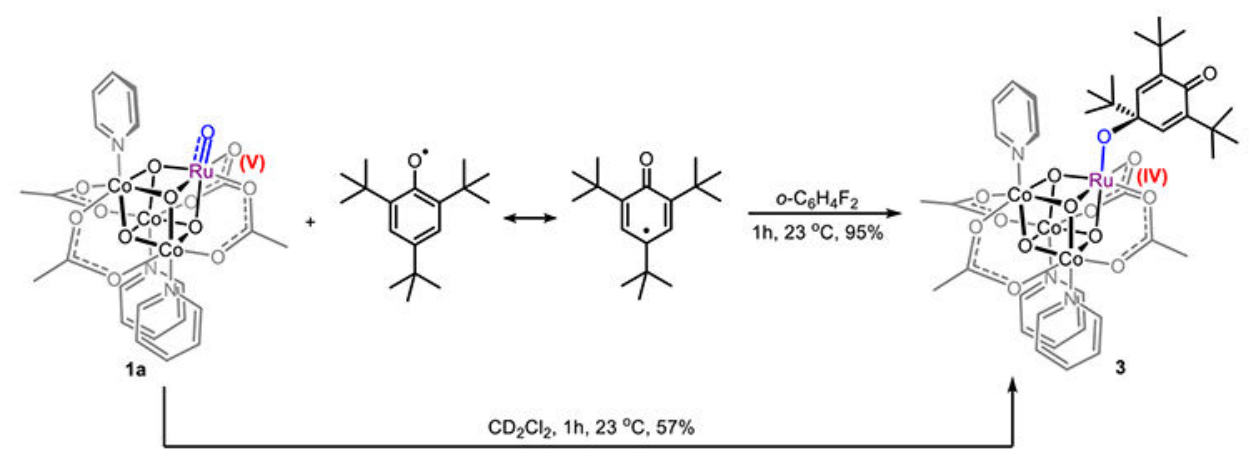<smiles>CC(C)(C)c1cc(C(C)(C)C)c(O)c(C(C)(C)C)c1</smiles>
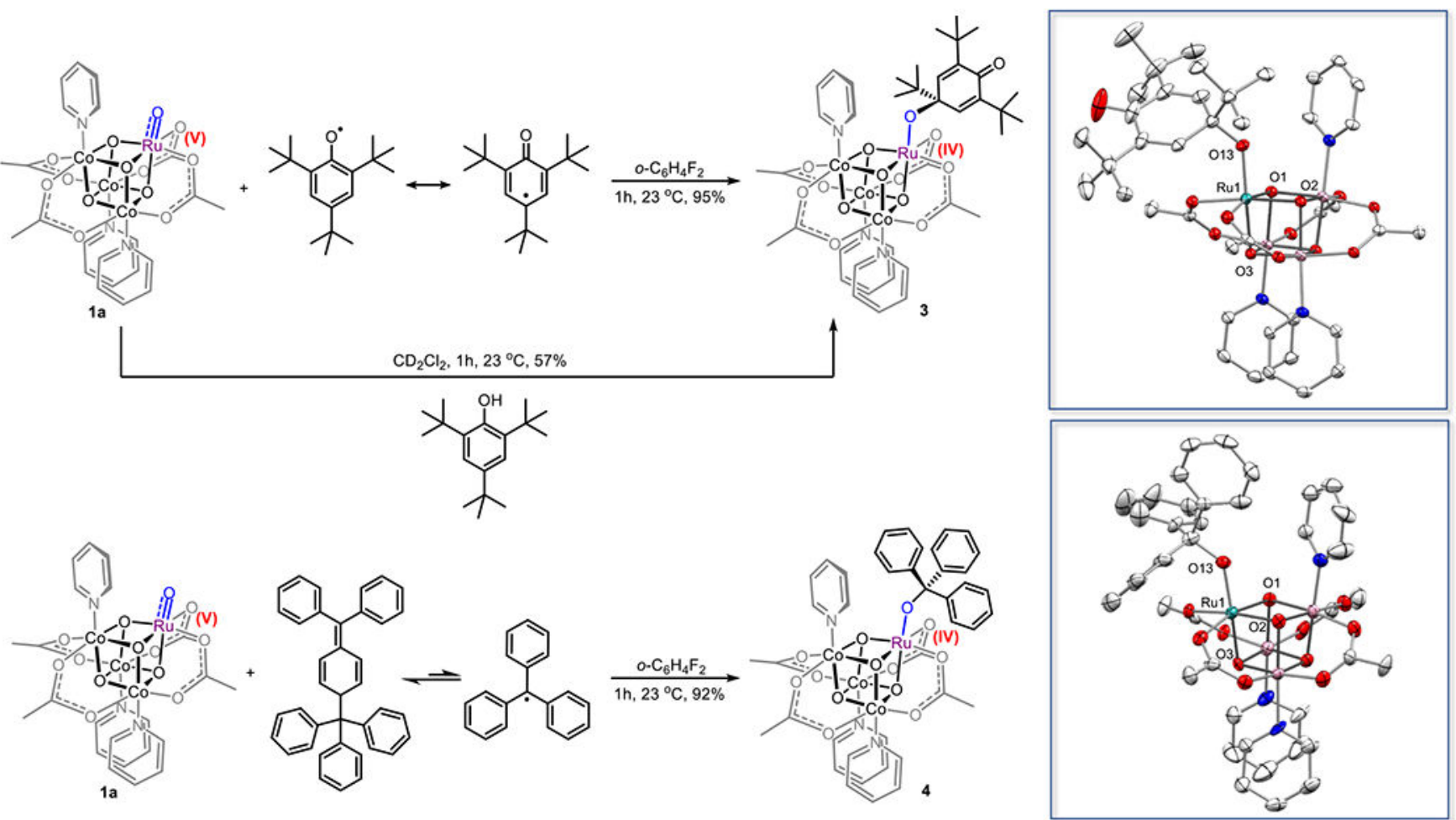

Scheme 3. Coupling Reactions of Organic Radicals and Terminal Ru ${ }^{\mathbf{V}}$-Oxo Cubane (1a) ${ }^{a}$

${ }^{a}$ Inset: Solid-state molecular structures of compounds $\mathbf{3}$ and $\mathbf{4}$. Solvents and hydrogen atoms are removed for clarity. Thermal ellipsoids are shown at 50\% and 30\% probability for $\mathbf{3}$ and 4 , respectively. 

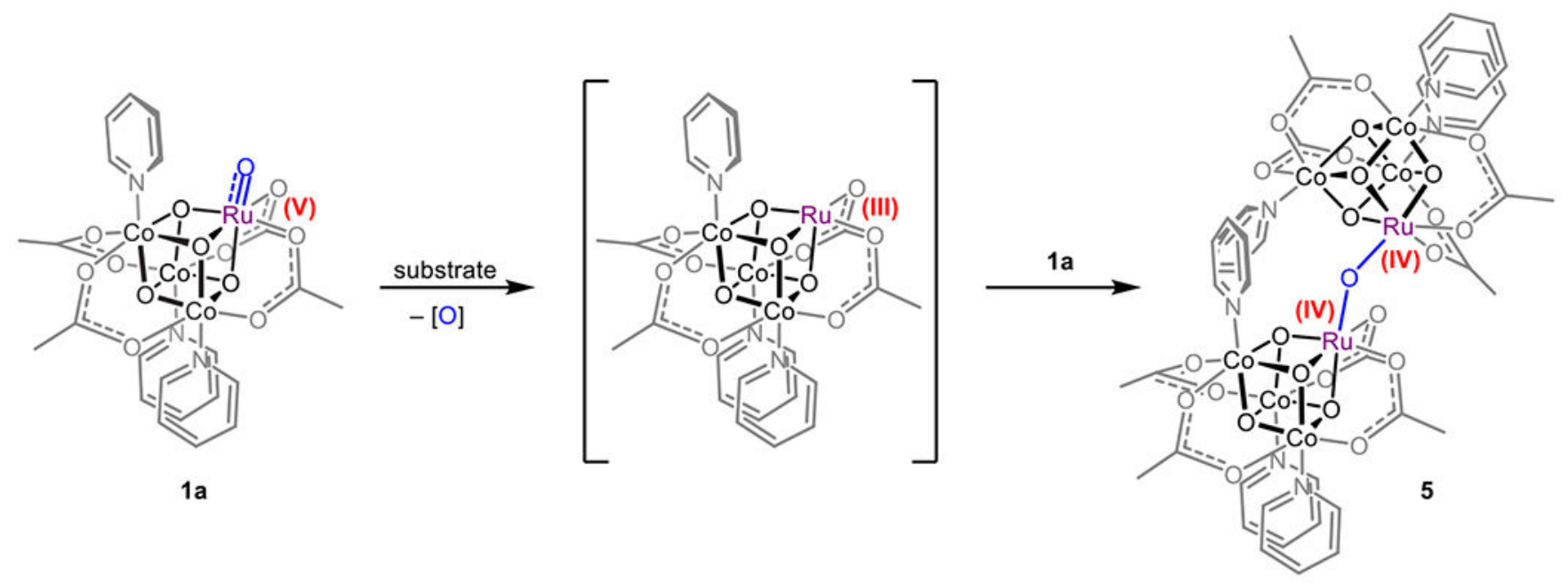

Scheme 4.

Proposed Mechanism for Transformation of 1a to 5 


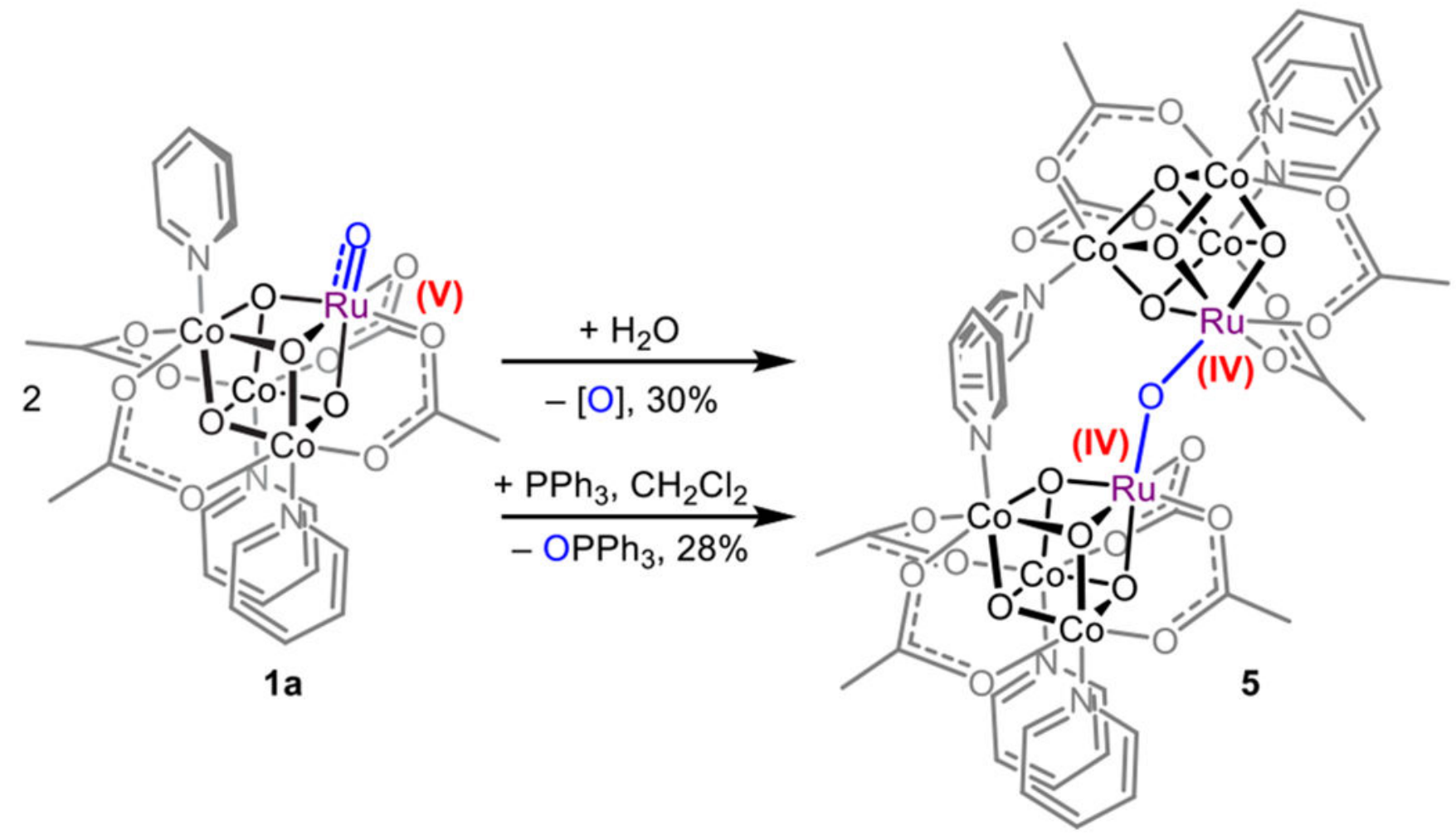

Scheme 5.

Synthetic Routes To Form the $\mu$-Oxo Bis-cubane Complex (5) 